\title{
Production of the Short Chain Fatty Acid, Acetic Acid/Acetate from Ethanol Metabolism Activates NMDAR
}

\author{
Andrew D. Chapp ${ }^{1,2}$, Michael J. Huber ${ }^{1,2}$, Kyle M. Driscoll ${ }^{2}$, Jessica E. Behnke ${ }^{1,2}$, Robert A. \\ Larson $^{1,2}$, Simeon Schum ${ }^{3}$, Zhiying Shan ${ }^{1,2}$, Li Zhang $^{4 *}$, Qing-Hui Chen ${ }^{1,2^{*}}$
}

\begin{abstract}
Affiliations:
${ }^{1}$ Department of Kinesiology and Integrative Physiology, Michigan Technological University, Houghton, MI 49931

${ }^{2}$ Department of Biological Sciences, Michigan Technological University, Houghton, MI 49931

${ }^{3}$ Department of Chemistry, Michigan Technological University, Houghton, MI 49931

${ }^{4}$ Laboratory for Integrative Neuroscience, National Institute on Alcohol Abuse and Alcoholism, National Institutes of Health, Rockville, MD 20852
\end{abstract}

Word Count:

Summary: 191

Introduction: 703

Results/Discussion: 3,881

Methods: 2,911

Figs--7

Supplemental Tables-1

Supplemental Figs--2

*Correspondence to:

Qing-Hui Chen, Ph.D.

Department of Kinesiology and Integrative Physiology,

Michigan Technological University.

SDC, 1400 Townsend Drive, Houghton, MI 49931 
Phone: (906) 487-1629; FAX: (906) 487-0985

Email:qinghuic@mtu.edu

Li Zhang, MD.

Laboratory for Integrative Neuroscience,

National Institute on Alcohol Abuse and Alcoholism.

National Institute of Health, Rockville, MD 20852

Phone: (301) 443-3755; Fax: (301) 480-0466

Email: lizhang@mail.nih.gov

Keywords: Short Chain Fatty Acid, Amygdala, Acetate, Acetic Acid, Acidification, Ethanol, NMDA Receptors, RVLM, Glutamate, CeA, Calcium 


\begin{abstract}
Short chain fatty acid (SCFA) regulation of neuronal function remains an interesting but poorly understood area of research. The SCFA, acetic acid, the main component of vinegar and the major metabolite of ethanol has been directly linked to altering neuronal function. However, the underlying mechanisms as it relates to alcohol consumption and SCFA regulation of neuronal function have yet to be elucidated. Here we show that local metabolism of ethanol to acetic acid/acetate in the central nucleus of amygdala (CeA) activates glutamatergic $N$-methyl- $D$ aspartate receptors (NMDAR) in vivo causing a sympathoexcitatory response. External acetate and intracellular loading of acetic acid in $\mathrm{CeA}$ neurons increased neuronal excitability through activation of NMDAR. Furthermore, cultured neurons exposed to acetate showed increased cytosolic calcium which response was abolished by NMDAR antagonist and decreased $\mathrm{pH}$. These findings suggest that acetic acid/acetate is an underestimated bioactive metabolite of ethanol that mediates some effects via an NMDAR-dependent mechanism in the brain. The link between the SCFA, acetic acid/acetate on increased neuronal excitability at least partially through NMDAR may provide a novel avenue for understanding alcohol, metabolic, cardiovascular and neurodegenerative disorders related to alterations in SCFA concentrations in the brain.
\end{abstract}




\section{Introduction}

Short Chain Fatty Acid (SCFA) regulation of neuronal function is a relatively new concept whereby SCFAs can alter ion channel gating properties (Carmichael et al., 1993; Chen et al., 1998; Drapeau and Nachshen, 1988), influence brain derived pro-inflammatory cytokines (Sampson et al., 2016) and modulate neurotransmitter release (Drapeau and Nachshen, 1988; Frost et al., 2014; Perry et al., 2016). Three SCFAs which are commonly explored are acetic acid/acetate, propionic acid/propionate and butyric acid/butyrate. The SCFA, acetic acid/acetate has been implicated in the central nervous system (CNS) inflammatory response and a contributor to the development of Parkinson's like symptoms in mice (Sampson et al., 2016). It has also been demonstrated to increase parasympathetic activity (Perry et al., 2016) and facilitate the release of both GABA and glutamate in the hypothalamus (Frost et al., 2014). Collectively these studies have suggested that the SCFA acetic acid/acetate has both excitatory and inhibitory modes of action within the brain. Inevitably these acetic acid/acetate induced responses in the CNS are due in large to alterations in ion channels and the cellular/molecular signaling mechanisms within the brain both from direct and most likely indirect modification of histone acetylation via increased acetyl-CoA (Webster, 1963).

The significance of the SCFA acetic acid/acetate from ethanol consumption and metabolism is one of great importance since alcohol is one of the most widely used and abused recreational substances. Acetic acid is the main component of vinegar and is generated in large quantities following ethanol ingestion and metabolism. The large acetate load can lead to significantly elevated serum and cerebrospinal fluid (CSF) concentrations of around 1-3 mM (Jiang et al., 2013; Wang et al., 2013) and 2-5 mM (Jiang et al., 2013; Wang et al., 2013), respectively. The concentration of acetate in circulation and CSF are also documented to remain 
elevated long after ethanol has cleared the body (Jiang et al., 2013). As such, it is therefore reasonable to suspect that acetic acid/acetate may be a likely player in the contribution to altered neuronal function following ethanol consumption and metabolism.

Precisely how ethanol produces excitatory effects in the CNS is largely unknown. On the one hand, increases in dopamine release in the ventral tegmental area (Brodie et al., 1999) facilitate reward and possible excitatory actions by the organism post ethanol ingestion, however this is partially contradicted by ethanol itself inhibiting NMDAR in slice recordings (Grover et al., 1994; Lovinger et al., 1990; Lovinger et al., 1989). Secondly, studies involving NMDAR inhibition by ethanol are commonly recorded in brain slice preparation (Hicklin et al., 2011; Lovinger et al., 1990; Lovinger et al., 1989) with large circulating volumes of ethanol relative to small tissue samples and therefore having very little enzymatic metabolism to generate significant acetic acid/acetate concentrations. What is known is that ethanol consumption contributes to excitatory actions originating within the CNS (Brodie et al., 1999; Karkhanis et al., 2016) with some positive modulatory action on NMDAR (Roh et al., 2011). Following ethanol clearance, excitation is exacerbated which can commonly be associated with hangover like symptoms (Karadayian et al., 2017; Wiese et al., 2000), of which acetate has been implicated (Maxwell et al., 2010). As such, increased excitability in pre-sympathetic neurons from acetate within the brain can initiate increases in SNA, mean arterial blood pressure (MAP) and heart rate (HR).

These sympathoexcitatory responses following acute ethanol ingestion have been observed in both humans (Carter et al., 2011; Randin et al., 1995) and animals (Hellstrom and Tottmar, 1982), however the precise cellular mechanisms which contribute to enhanced SNA from ethanol remain to be elucidated. Our lab has previously reported that microinjection of ethanol and acetate into the central nucleus of amygdala (CeA) an area containing pre-sympathetic neurons with axon 
projecting to the rostral ventrolateral medulla (CeA-RVLM) involved the local activation of NMDAR (Chapp et al., 2014). We hypothesized that local metabolism of ethanol resulting in the generation of the SCFA, acetic acid/acetate was the main NMDAR excitatory component (Fig 2S). Herein we show in vivo that local microinjection of ethanol within the CeA and activation of NMDAR is metabolically dependent through the generation of acetic acid/acetate. We further demonstrate in vitro that bath application of acetate increases CeA-RVLM neuronal excitability and mediates inward currents, both via NMDAR activation.

\section{RESULTS}

Peripheral administration of EtOH increases acetate concentrations in serum, csf and amygdala tissue

Previous studies have demonstrated elevated acetate concentrations following EtOH administration (Jiang et al., 2013; Wang et al., 2013). To demonstrate that peripheral administration of EtOH increases acetate concentrations, rats were given an intraperitoneal injection of either EtOH $(2 \mathrm{~g} / \mathrm{kg})$ or a caloric/volume control of glucose. In aggrement with previously published results, peripheral EtOH increased csf and serum concentrations of acetate (Fig 1S). Likewise, amygdala tissue also showed increased levels of acetate. This data suggests that peripheral metabolism of EtOH generates large quantities of the SCFA, acetic acid which subsequently deprotonates to acetate which is circulated systemically and accumulates in amygdala tissue (Fig 1S).

\section{Local metabolism of ethanol to acetate in CeA activates NMDAR in vivo}


Previous reports have indicated ethanol actions on a multitude of neurotransmitters and receptors in the CNS; GABA (Mihic et al., 1997), glutamatergic receptors (Siggins et al., 2003), including NMDAR (Lovinger et al., 1989; Mameli et al., 2005; Siggins et al., 2003), acetylcholine (Strong et al., 1987), glycine (Mascia et al., 1996) and dopamine (Boileau et al., 2003). These findings have produced mixed results as ethanol is implicated in both excitatory and inhibitory actions in the CNS. Our lab previously reported that ethanol and acetate microinjected into the $\mathrm{CeA}$ of anesthetized rats resulted in a sympathoexcitatory effect and speculated that it was due to local metabolism of ethanol to acetate (Chapp et al., 2014). Consistent with our previous findings, microinjection of ethanol into the CeA of anesthetized rats elicited a sympathoexcitatory and pressor response (Fig 1B,D). Since we speculated that this sympathoexcitatory response was due to local metabolism of ethanol to acetate (Fig 1A), we co-applied ethanol with an aldehyde dehydrogenase inhibitor (ALDH), cyanamide (Demaster et al., 1983), into the CeA (Fig 1C,E). Blockade of ALDH with cyanamide significantly blunted the sympathoexcitatory response from ethanol, indicating that neither ethanol nor acetaldehyde was likely a causitive agent in the excitatory response.

Next, we verified that acetate was the bioactive metabolite from ethanol metabolism. Microinjection of acetate into the CeA of anesthetized rats increased sympathetic nerve activity (SNA) and mean arterial blood pressure (MAP) in a dose dependent manner (Fig 1F-J). Our initial hypothesis regarding acetate activation of NMDAR involved the theory that the carboxy terminals of glutamate were mimicked by partial agonism of two acetate molecules within the glutamate binding pocket (Fig 1A). Memantine has seen utilization in alcohol studies (Alaux-Cantin et al., 2014; Idrus et al., 2014) to prevent cognitive decline and as a possible therapeutic for excitotoxicity (Zhou et al., 2013). Furthermore, it is an FDA approved NMDAR blocker for the treatment of 
alzhiemer's disease (van Marum, 2009), which would give more powerful treatment options compared to utilizing AP5 as previously described (Chapp et al., 2014). Consistent with our previous publication utilizing AP5, blockade of NMDAR within the CeA significantly attenuated the acetate induced sympathoexcitatory and pressor responses suggesting that increases in SNA and MAP were due to acetate activation of NMDAR (Fig 1G-J).

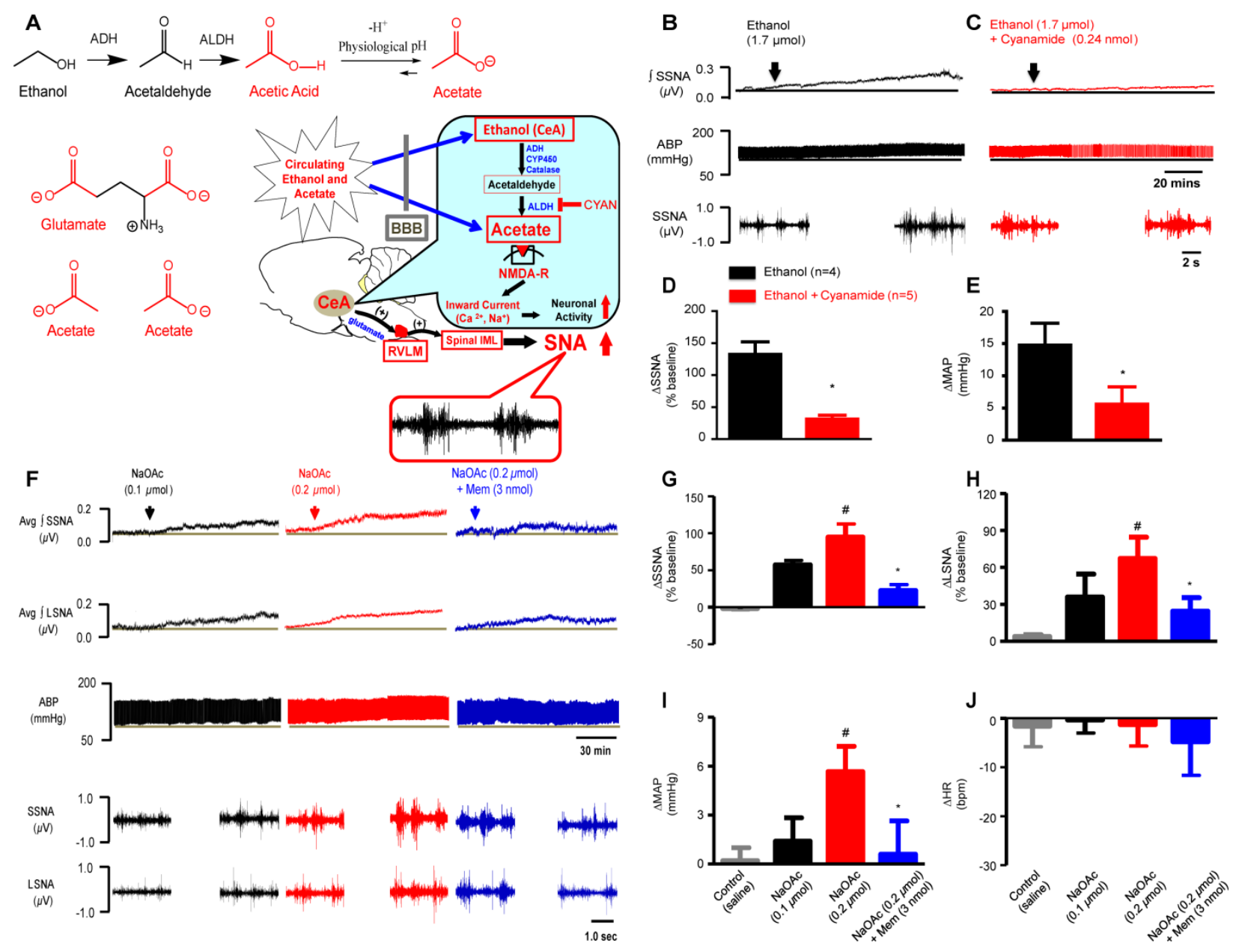

Fig 1. Sympathoexcitatory and pressor effect of ethanol and acetate is NMDAR dependent.

(A) Working hypothesis model for ethanol and acetate induced sympathoexcitation. Metabolic pathway for ethanol (top, left), excitatory neurotransmitter glutamate (middle, left) and acetate (bottom, left). Microinjected ethanol into the CeA is metabolized locally to acetate which activates NMDAR (bottom, right). Blockade of aldehyde dehydrogenase (ALDH) with cyanamide (CYAN) 
reduces production of bioactive acetate. (B) Representative raw trace of sympathetic nerve recording (SNA) to CeA micorinjected ethanol in anesthetized rats. (C) Representative raw trace of SNA to cocktail of ethanol and cyanamide in the CeA of anesthetized rats. (D) Summary splachnic SNA (SSNA) data for CeA microinjected ethanol and ethanol/cyanamide in anesthetized rats. (* $\mathrm{P}<0.05$ vs ethanol) (E) Summary data for mean arterial blood pressure (MAP) to CeA microinjected ethanol and ethanol/cyanamide in anesthetized rats. ( $* \mathrm{P}<0.05$ vs ethanol) (F) Representative raw traces for SNA and MAP nerve recordings to varying doses of CeA micronjected sodium acetate $(\mathrm{NaOAc})$ and $\mathrm{NaOAc} /$ memantine (NMDAR blocker). Low dose

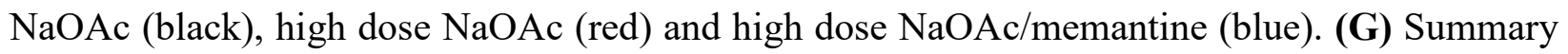
SSNA data for NaOAc dose response and NMDAR blocker data. (\# $\mathrm{P}<0.05$ vs control, * $\mathrm{P}<0.05$ vs NaOAc (0.2 $\mu$ mole). (H) Summary lumbar SNA data for NaOAc dose response and NMDAR blocker data. (\# $\mathrm{P}<0.05$ vs control, $* \mathrm{P}<0.05$ vs NaOAc $(0.2 \mu$ mole). (I) Summary MAP data for $\mathrm{NaOAc}$ dose response and NMDAR blocker data. (\# $\mathrm{P}<0.05$ vs control, $* \mathrm{P}<0.05 \mathrm{vs} \mathrm{NaOAc}$ (0.2 $\mu$ mole). (J) Summary heart rate (HR) data for NaOAc dose response and NMDAR blocker data. Abbreviations: ADH (alcohol dehydrogenase), ALDH (aldehyde dehydrogenase), CYP450 (cytochrome p450), RVLM (rostral ventrolateral medulla), IML (intermediolateral column), NMDAR ( $N$-methyl-D-aspartate receptor).

\section{Bath application of acetate increases CeA-RVLM neuronal excitability through activatation of NMDAR}

To further corroborate our in vivo microinjection with acetate activation of NMDAR in the CeA, we examined whether acetate was capable of increasing neuronal excitability of presympathetic CeA neurons with projections to the rostral ventrolateral medulla (CeA-RVLM) in 
brain slice preparation. The RVLM as we and others have previously reported (Chapp et al., 2014; Chen and Toney, 2010; Lin et al., 1995) is a key source of sympathoexcitatory drive that can contribute to elevated sympathetic outflow and heavily regulates cardiovascular function. What we found was that extracellular acetate consistently increased CeA-RVLM neuronal excitability in a dose-dependent manner with an $\mathrm{EC}_{50}$ value of $6.94 \mathrm{mM}$ (Fig 2B). This value is close to peak acetate concentrations of $\sim 4.60 \mathrm{mM}$ measured by Wang and colleagues in ethanol and acetate infused rats (Wang et al., 2013). We must point out, our dose of $37.5 \mathrm{mM}$ acetate was utilized to obtain the maximum effect both for our excitability study as well as our NMDAR mediated inward current study.

To verify that NMDAR were involved in the acetate induced increase in CeA-RVLM neuronal excitability, we used two NMDAR blockers, AP5 (NMDAR competitive antagonist) and memantine (non-competitive pore blocker). Our initial hypothesis was that ethanol metabolism to acetate mimicked carboxy terminals in the binding pocket for glutamate (Fig 1A). Consistent with this hypothesis, co-application of acetate and AP5 was only able to slightly reduce neuronal excitability (Fig 2E-G) while co-application of acetate and memantine (Fig 2E-G) was able to completely abolish the acetate induced increase in CeA-RVLM neuronal excitability. This suggests that both acetate and AP5 had competition for the glutamate binding pocket resulting in the slight reduction seen in both excitability and slope (Fig 2E-G). Memantine on the other hand was capable of abolishing the acetate effects because NMDAR pore blocking from memantine occurs regardless of active glutamate site binding/activation (Parsons et al., 1993). Thus we found that memantine was more effective in abolishing the acetate induced increase in neuronal excitability compared to AP5. 


\section{Bath application of acetate increases depolarizing input resistance and causes a hyperpolarizing shift in voltage threshold to firing an action potential in CeA-RVLM neurons}

To further understand the effects of external acetate on CeA-RVLM neuronal excitability, neurons were subjected to a ramp protocol aimed to explore voltage threshold for firing an action potential $\left(\mathrm{V}_{\mathrm{t}}\right)$ and depolarizing input resistance $\left(\mathrm{R}_{\text {input }}\right.$ (Fig $\left.2 \mathrm{H}-\mathrm{J}\right)$. Two major findings were observed from our ramp protocol with regards to external acetate; first, acetate increased the $\mathrm{R}_{\text {input }}$ compared to control (Fig 2I). From an excitability standpoint, increased $\mathrm{R}_{\text {input }}$ suggests an increase of positive ion influx in acetate treated neurons compared to control. The effect of NMDAR blockers had a trend to reduce depolarizing input resistance, although the effect was not statistically significant (Fig 2I).

The second interesting observation was the ability of acetate to induce a hyperpolarizing shift in the voltage threshold to firing an action potential (Fig 2J). Our control neurons had a mean $\mathrm{V}_{\mathrm{t}}$ of $\sim-44 \mathrm{mV}$; acetate shifted the mean $\mathrm{V}_{\mathrm{t}}$ to $\sim-49 \mathrm{mV}($ Fig $2 \mathrm{H}, \mathrm{J})$, suggesting that not only does acetate affect NMDAR, but also is capable of modulating voltage gated sodium channels. There is some evidence in hippocampal neurons to suggest that $\mathrm{pH}$ can affect voltage gated sodium channels, with alkalinzation causing a hyperpolarizing shift and acidification causing a depolarizing shift (Tombaugh and Somjen, 1996). Indeed, acetate (37.5 mM) alkalinized the external bath solution from $\mathrm{pH} \sim 7.35$ to $\mathrm{pH} \sim 7.6-7.65$, and these acid/base disorders have been noted in alcohol intoxication (Kalaitzidis, 2015; Zehtabchi et al., 2005). To the best of our knowledge, we are the first to report this effect in neurons with regard to acetate; to what extent $\mathrm{pH}$ fluctuations from alcohol use play in changes in voltage gated sodium channel gating properties remains to be explored. $\mathrm{pH}$ can also affect NMDAR, with external alkalinization potentiating and 
external acidification inhibiting NMDAR (Chen et al., 1998; Gottfried and Chesler, 1994), thus besides direct NMDAR activation, $\mathrm{pH}$ activation or inhibition is also possible.

\section{Bath application of acetate induces NMDAR mediated inward currents in CeA-RVLM neurons}

Next we examined whether external acetate application resulted in NMDAR mediated inward currents in CeA-RVLM neurons. From our excitability study, memantine was found to be more effective at reducing CeA-RVLM neuronal excitability and was therefore used as our choice NMDAR antagonist for the NMDAR mediated inward current study. What we found consistent with our excitability study was that bath application of acetate significantly increased NMDAR mediated inward currents (Fig 2K). Co-application of acetate and memantine was able to completely abolish NMDAR mediated inward currents (Fig 2K,L). Since we were applying acetate as a sodium salt, we wanted to verify that the increased NMDAR mediated inward currents were not due to increased sodium concentration. As such, we used sodium gluconate as a sodium ion control and found that $37.5 \mathrm{mM}$ sodium gluconate was unable to trigger any NMDAR mediated inward currents (Fig 2K), suggesting acetate was the bioactive compound. 

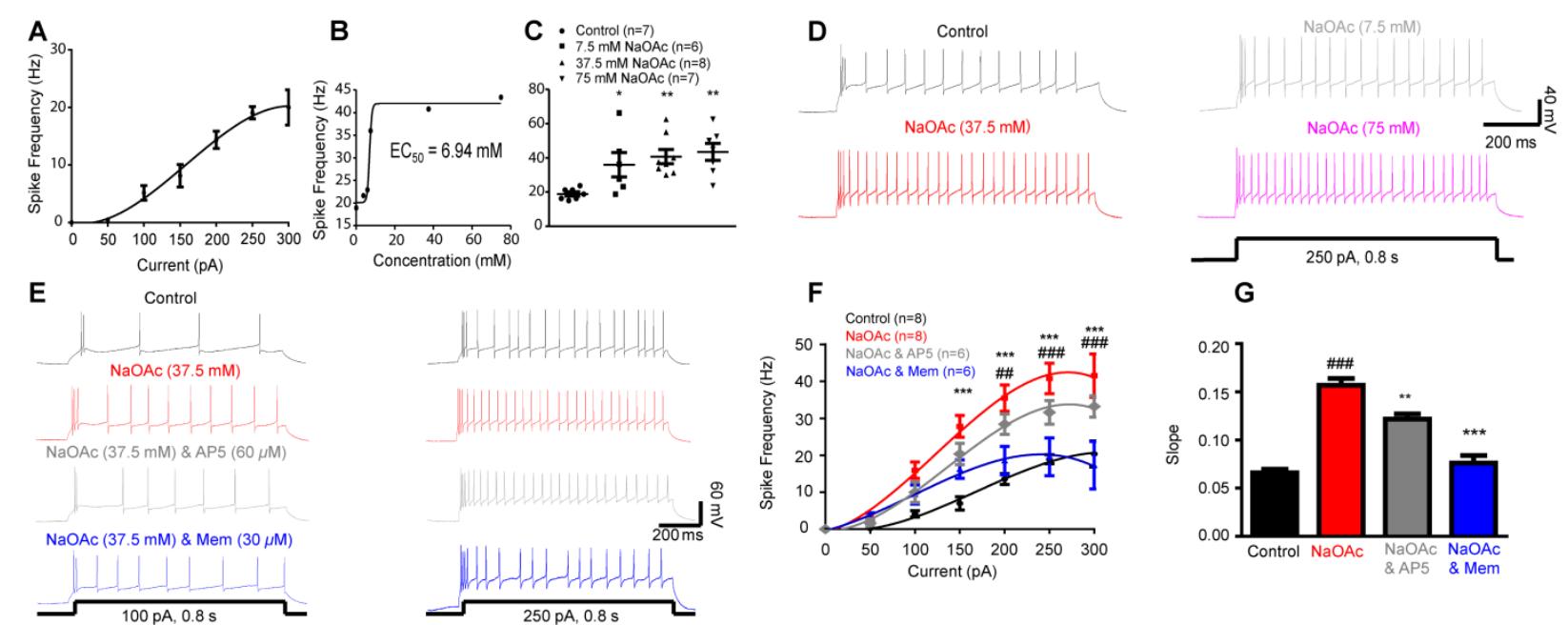

G
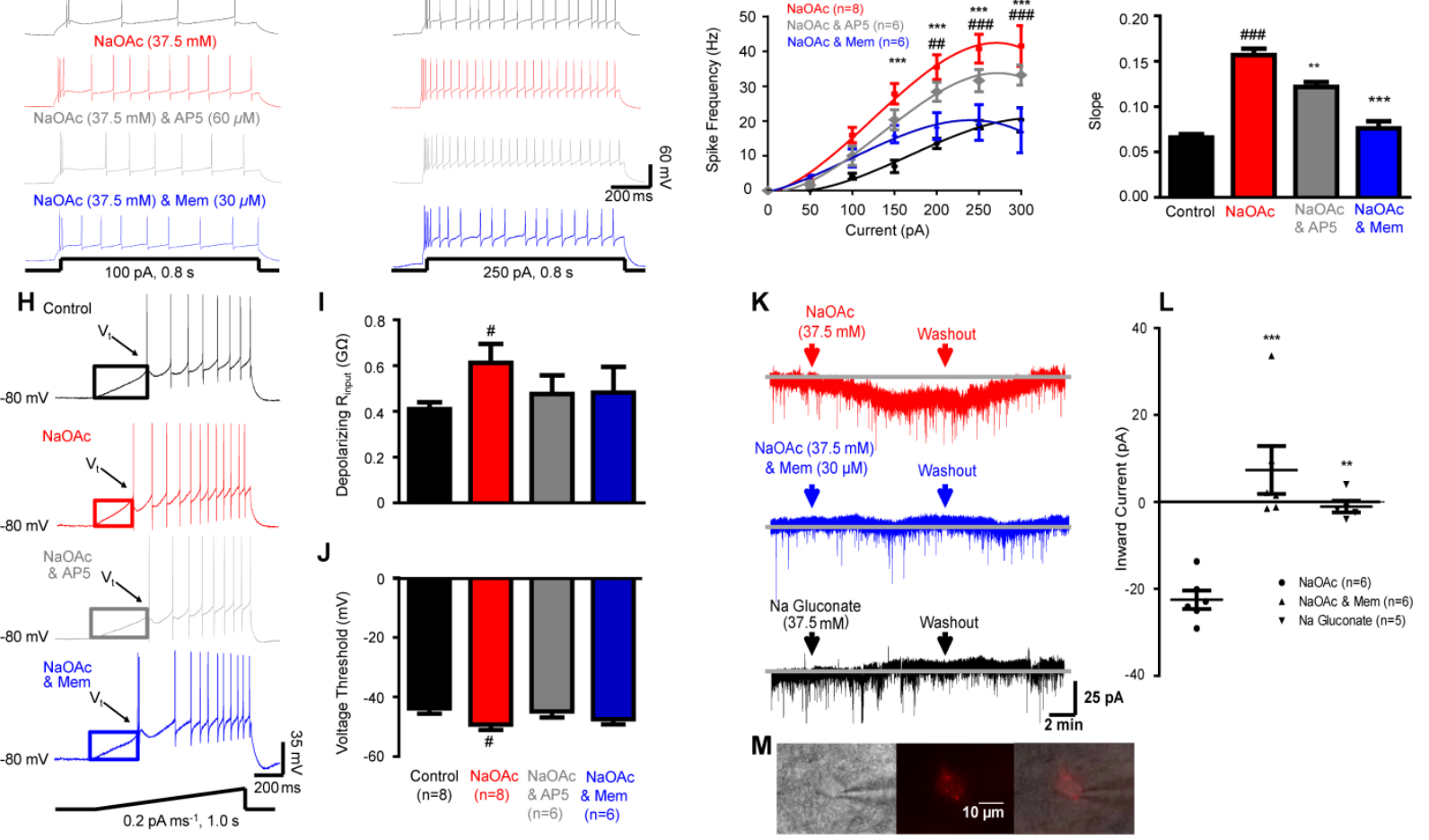

Fig 2. Acetate increases CeA-RVLM neuronal excitability through activation of NMDAR.

(A) Stimulus response curve for CeA-RVLM neurons. Maximum firing occurred at $+250 \mathrm{pA}$ current injection. (B) Dose-dependent response curve for sodium acetate (NaOAc) on firing frequency at $+250 \mathrm{pA}$ current injection. The $\mathrm{EC}_{50}$ value for $\mathrm{NaOAc}$ was $6.94 \mathrm{mM}$. (C) Summary data for control, and $\mathrm{NaOAc}(7.5,37.5$ and $75 \mathrm{mM})$. (* $\mathrm{P}<0.05, * * \mathrm{P}<0.01$ vs control). (D) Representative raw excitability traces for varying doses of acetate to $+250 \mathrm{pA}$ current injection. (E) Representative raw traces for control (black), NaOAc (37. 5 mM, red), NaOAc \& AP5 (grey) and NaOAc \& memantine (blue) at +100 pA (left) and +250 pA (right). (F) Current stimulus response for control (black), NaOAc (red), NaOAc \& AP5 (grey) and NaOAc \& memantine (blue). 
(*** $\mathrm{P}<0.001 \mathrm{NaOAc}$ vs control, \#\# $\mathrm{P}<0.01$, \#\#\# $\mathrm{P}<0.001 \mathrm{NaOAc}$ vs NaOAc \& memantine).

(G) Slope of the stimulus response in control (black), NaOAc (red), NaOAc \& AP5 (grey) and NaOAc \& memantine (blue). (\#\#\# $\mathrm{P}<0.001$ vs control, ** $\mathrm{P}<0.01$, *** $\mathrm{P}<0.001$ vs NaOAc). (H) Representative raw traces for ramp excitability protocol for control (black), NaOAc (red), NaOAc \& AP5 (grey) and NaOAc \& memantine (blue). (I) Summary data for depolarizing $\mathrm{R}_{\text {input. }}$ (\# $\mathrm{P}<0.05$ vs control). (J) Summary data of voltage threshold to firing an action potential. (\# $\mathrm{P}$ $<0.05$ vs control). (K) Representative raw traces for NMDAR mediated inward currents in CeARVLM neurons. (L) Summary data for NMDAR mediated inward currents in CeA-RVLM neurons. (*** $\mathrm{P}<0.001, * * \mathrm{P}<0.01$ vs NaOAc). (M) Representative CeA-RVLM neuron; differential interference contrast (DIC, left), epifluorescence of the same neuron from retrograde RVLM fluorescent labeling (middle), merged DIC/epifluorescence indicating CeA neuron with projection to RVLM (right).

\section{Bath application of acetate to primary neuronal cultures increases cytosolic calcium and acidifies neurons}

There is substantial literature which also suggests that weak organic acids such as lactic acid, proprionic acid and acetic acid are capable of acidifying cells due to their rapid transport across cell membranes (Chen et al., 1998). Chen and colleagues reported that at developing neuromuscular synapses, external application of two conjugate bases (CB) of SCFAs, acetate (CB of acetic acid) and propionate ( $\mathrm{CB}$ of propionic acid) increased spontaneous synaptic currents and potentiated NMDAR responses to agonists due to internal acidification (Chen et al., 1998). We wanted to confirm whether external acetate application to primary neuronal cultures was able to 1) increase cytosolic calcium measured in real-time using a cytosolic calcium fluorescent probe 
(Fluo4-AM) and 2) confirm that external acetate caused neuronal acidification. Bath application of acetate $(37.5 \mathrm{mM}$, exact as those used in patch clamp recordings) increased cytosolic calcium and increased the $\left[\mathrm{H}^{+}\right]$concentration in a time dependent manner within neurons and glial cells (Fig $3 \& 4)$.

A

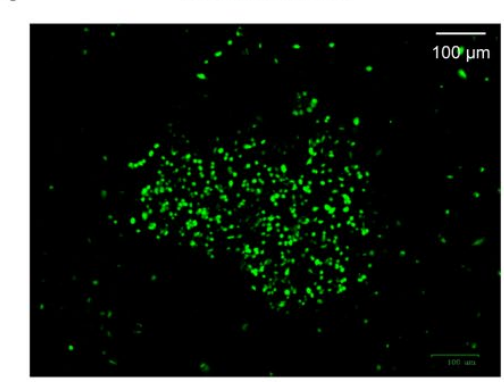

B

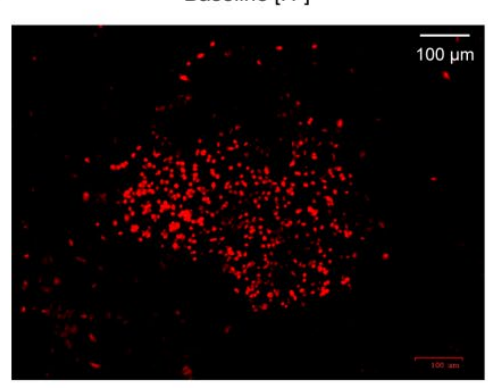

C

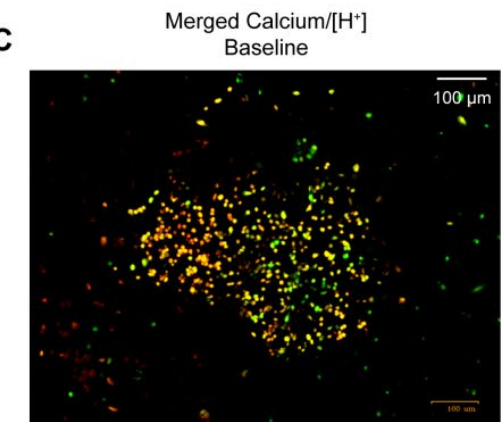

D

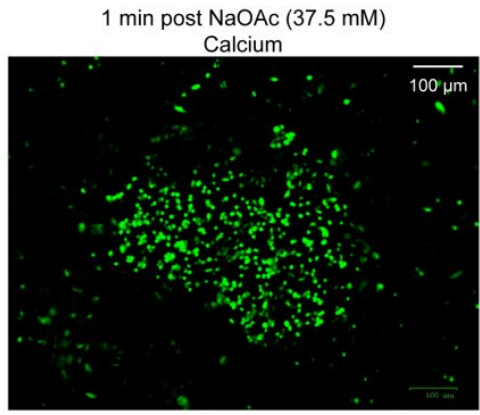

E

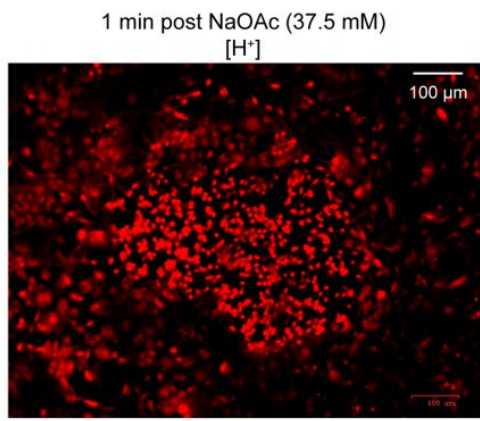

$\mathbf{F}$



G

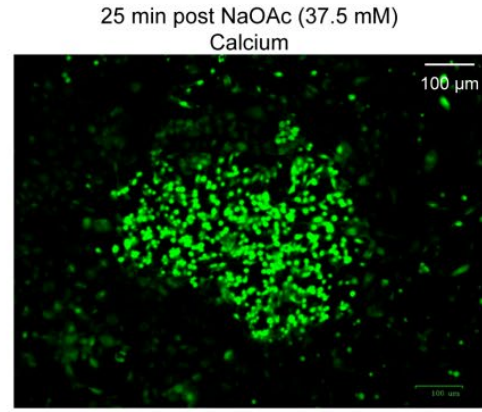

H

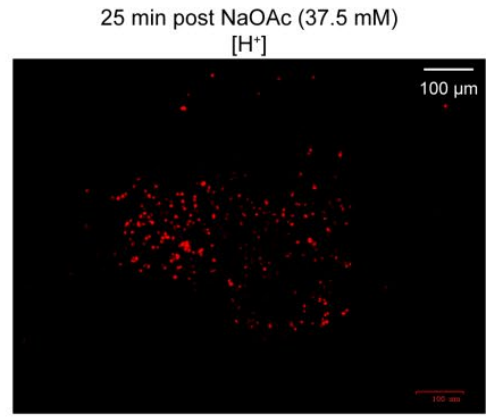

Merged Calcium/[H+ $\left.\mathrm{H}^{+}\right]$ $25 \mathrm{~min}$ post $\mathrm{NaOAc}(37.5 \mathrm{mM})$

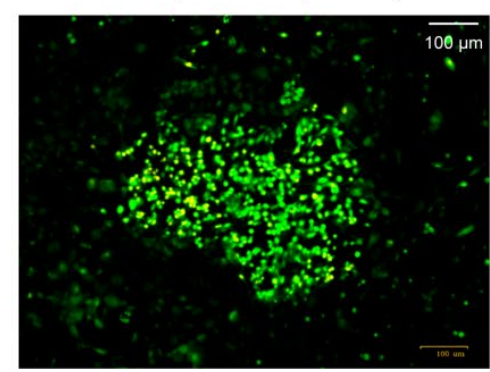

Fig 3. Acetate increases cytosolic calcium and acidifies neurons and glial cells. (A) Baseline

calcium fluorescence. (B) Baseline pH fluorescence, increased fluorescence indicates decreased pH. (C) Merged calcium and pH images. (D) 1 minute post $\mathrm{NaOAc}$, calcium fluorescence. (E) 1 min post NaOAc, $\mathrm{pH}$ fluorescence. (F) Merged calcium and $\mathrm{pH}$ images. (G) 25 minutes post NaOAc, calcium fluorescence. (H) 25 minutes post NaOAc, pH fluorescence. (I) 25 minutes post $\mathrm{NaOAc}$, merged calcium and $\mathrm{pH}$ images. 
A

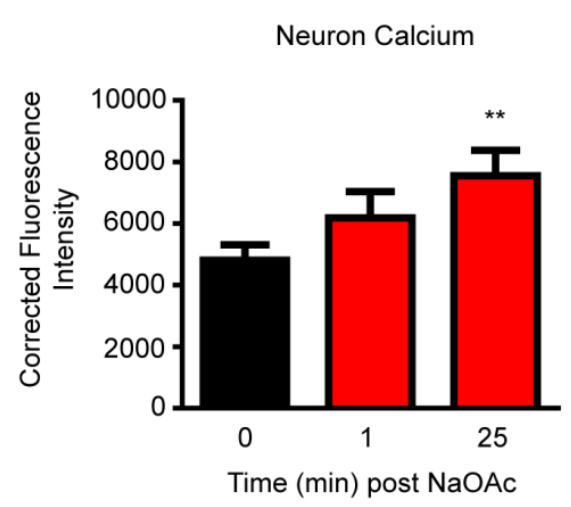

C

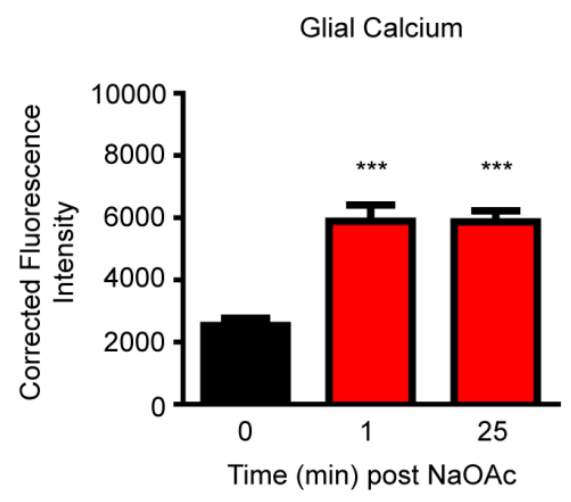

B

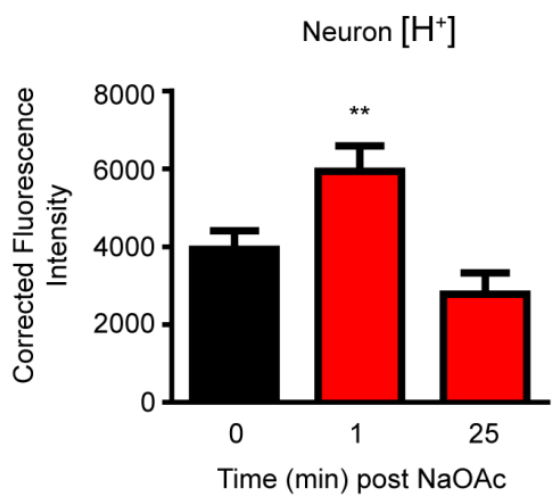

D

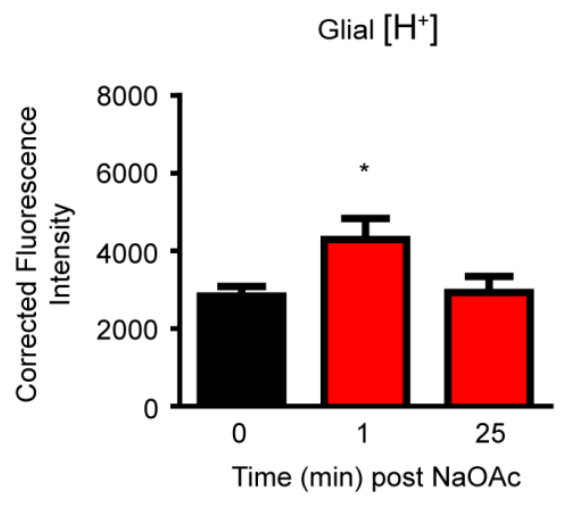

Fig 4. Summary data for image fluorescence intensity quantification from neurons and glial cells with acetate. (A) Neuronal calcium time course with $\mathrm{NaOAc}$ (** $\mathrm{P}<0.01$ vs baseline). (B) Neuronal $\left[\mathrm{H}^{+}\right]$time course with $\mathrm{NaOAc}$, increased fluorescence indicates decreased $\mathrm{pH}(* * \mathrm{P}<$ 0.01 vs baseline). (C) Glial calcium time course with NaOAc (*** $\mathrm{P}<0.001$ vs baseline). (D) Glial $\mathrm{pH}$ time course with $\mathrm{NaOAc}(* \mathrm{P}<0.05$ vs baseline).

Intraneuronal acidification with acetic acid increases CeA-RVLM neuronal excitability and involves NMDAR 
To further investigate what effect neuronal acidification had on CeA-RVLM neuronal excitability, we explorered the effect of external application of $6 \mathrm{mM}$ acetate which was near our $\mathrm{EC}_{50}$ value of $6.94 \mathrm{mM}$ (Fig 2B) from patch clamp recordings on primary neuronal culture acidification. Similar to our high dose of acetate, low dose acetate significantly increased neuronal $\left[\mathrm{H}^{+}\right]$concentration. (Fig 5A). Next, we internally loaded CeA-RVLM neurons with acetic acid via our recording electrode. For the acetic acid load, we felt it more important to keep the $\mathrm{pH}$ fixed, rather than keeping the acetic acid load fixed. Based on our $\mathrm{EC}_{50}$ curve, we added $7.5 \mathrm{mM}$ acetic acid to our batch of recording solution and noted the $\mathrm{pH}$ dropped from $\sim 7.3$ to 5.2. Future recording solutions were kept at constant $\mathrm{pH}=5.2$ with the acetic acid final concentration ranging between 6-15 mM, consistent with our external acetate $\mathrm{EC}_{50}$ (Fig 5B).

Neurons internally loaded with acetic acid $(\mathrm{pH}=5.2)$ were found to have increased excitability compared to control $(\mathrm{pH}=7.3)($ Fig 5C) as indicated by the current injection response and slope of the response (Fig 5C-E). NMDAR blocker, memantine was only able to reduce the slope of the stimulus response in the early depolarization phase induced by internal acetic acid load (Fig 5C-E). Different from external acetate challenge, memantine had no effect on maximum firing and excitability from internally loaded acetic acid (Fig 5C) and did not prevent acidification (Fig 6\&7). Consistent with our ramp protocol from external acetate, internal acetic acid load in CeA-RVLM neurons also increased depolarizing input resistance (Fig 3E). Memantine had no effect on the reduction in depolarizing input resistance (Fig 3F-G), at least partially due to the acid labile proton (cation) from the internal acetic acid load (Fig 6\&7). Secondly, the internal acetic acid load also caused a hyperpolarizing shift in $\mathrm{V}_{\mathrm{t}}$ to about $-49 \mathrm{mV}$ (Fig 3F,H), consistent with external acetate challenge (Fig 4J) and consistent with acid/base fluctuations affecting gating properties of voltage gated sodium channels (Tombaugh and Somjen, 1996). 
A

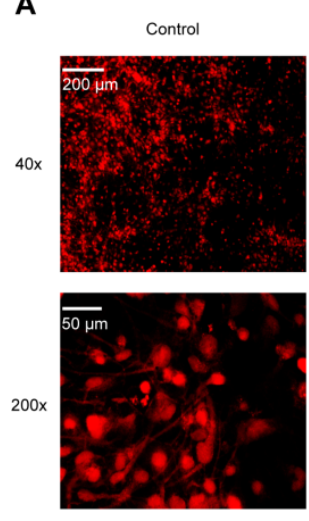

E

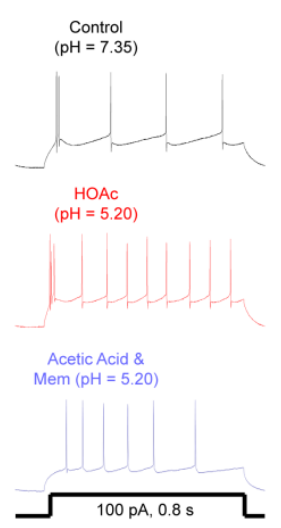

B
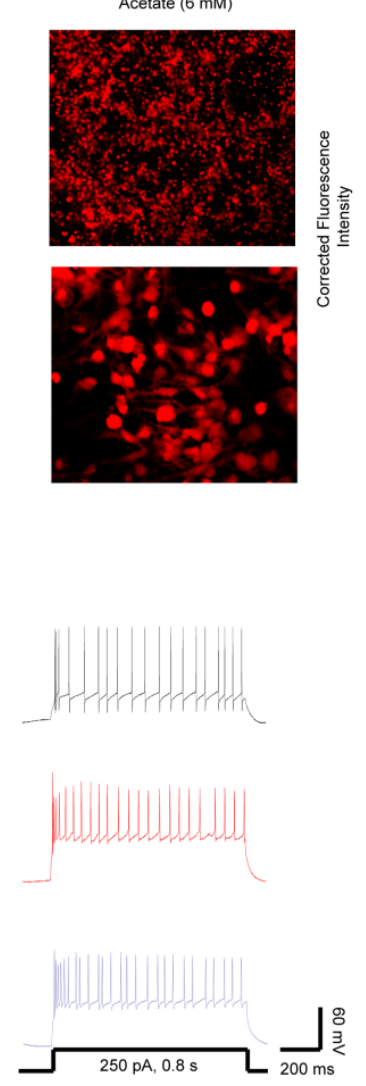

$\mathbf{F}$
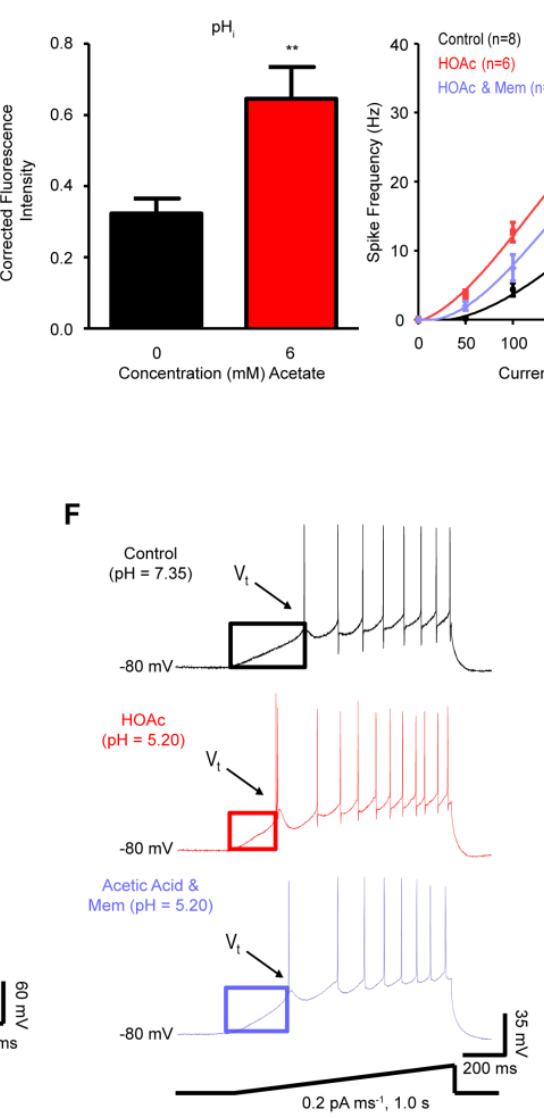

D

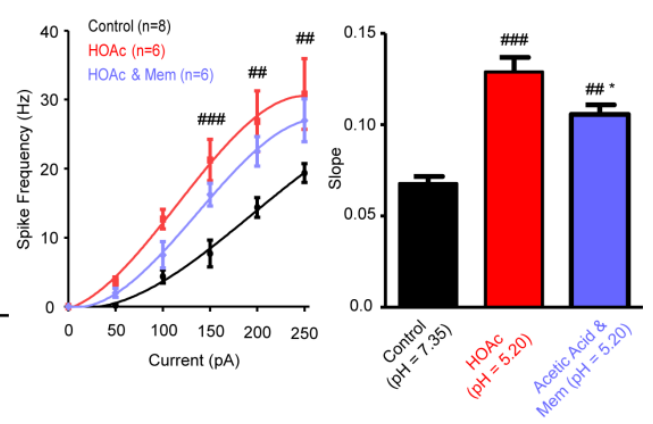

G

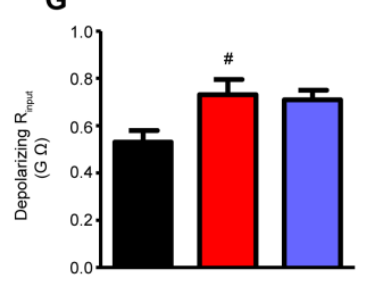

$$
\text { H }
$$

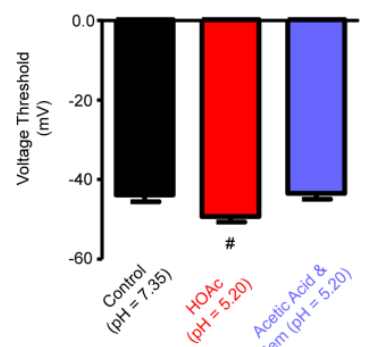

Fig 5. Intracellular loaded acetic acid increases CeA-RVLM neuronal excitability through activation of NMDAR. (A) External acetate (NaOAc, $6 \mathrm{mM}$ ) decreased neuronal $\mathrm{pH}$ measured in real-time using a $\mathrm{pH}$ sensitive fluorescent probe in primary neuronal cultures. (B) Corrected fluorescence intensity for primary cultured neurons exposed to control (black) or $\mathrm{NaOAc}$ (red). (** $\mathrm{P}<0.01$ vs control) (C) Current stimulus response for control (black), acetic acid (HOAc, $\mathrm{pH}$ $=5.2$, red) loaded cells and HOAc \& external memantine (blue). (\#\#\# $\mathrm{P}<0.001 \mathrm{NaOAc}$ vs control) (D) Slope of the stimulus response for control (black), HOAc (red) and HOAc \& memantine (blue). (\#\# $\mathrm{P}<0.01$ vs control, * $\mathrm{P}<0.05$ vs NaOAc). (E) Representative raw traces to $+100 \mathrm{pA}$ (left) and +250 pA (right) for control (black), HOAc (red) and HOAc \& memantine (blue). (F) Representative raw traces for ramp protocol to internally loaded HOAc and NMDAR blocker. (G) 
Summary data for depolarizing $\mathrm{R}_{\text {input }}$ in control (black), HOAc (red) and HOAc \& memantine (blue) cells. (\# $\mathrm{P}<0.05$ vs control). (H) Summary data for voltage threshold $\left(\mathrm{V}_{\mathrm{t}}\right)$ to firing an action potential. (\# $\mathrm{P}<0.05$ vs control).

Bath application of acetate with memantine abolishes acetate induced increases in cytosolic calcium but has no affect on acidification in primary neuronal cultures

Our patch clamp recordings that involved intraneuronal acidification with acetic acid $(\mathrm{pH}$ $=5.20$ ) demonstrated that dropping neuronal $\mathrm{pH}$ had positive modulatory effects on NMDAR in early depolarization. NMDAR blocker was able to partially normalize the early depolarization phase (0-100 pA), however it had no effect on reducing maximum firing with acetic acid loaded neurons (Fig 5C). We therefore wanted to determine the effect of NMDAR blocker on acetate induced acidification and increases in cytosolic calcium in primary neuronal culture. Consistent with our NMDAR mediated inward current recordings and excitability data, memantine (30 $\mu \mathrm{M}$, exact as patch clamp experiments) abolished the acetate induced increase in cytosolic calcium (Fig $6 \& 7$ ), however it had no effect on abolishing increases in $\left[\mathrm{H}^{+}\right]$concentrations in neurons or glia (Fig 6 \& 7). This finding was in agreement with literature reports regarding acetate (Chen et al., 1998; Drapeau and Nachshen, 1988) and suggests that acidification may be an imporant component in itself to enhanced excitability, independent of NMDAR. 
A

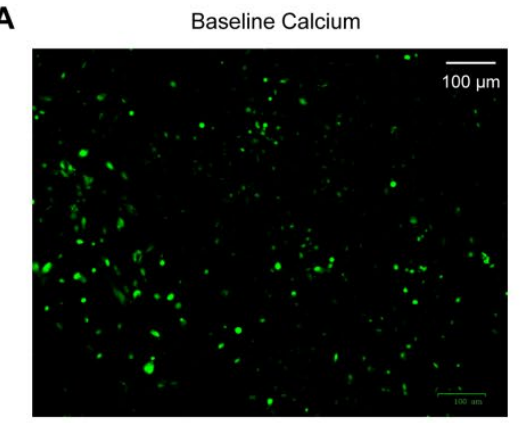

B

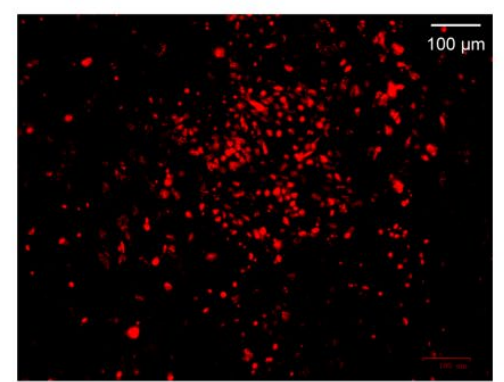

C

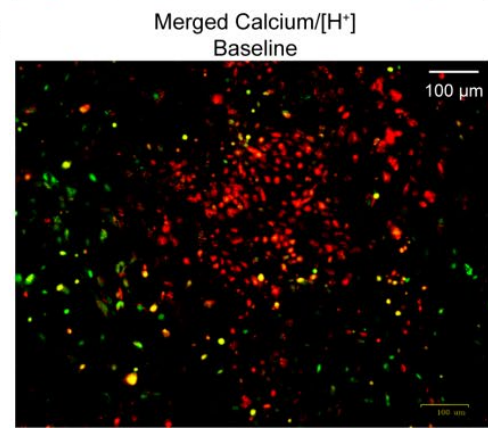

D

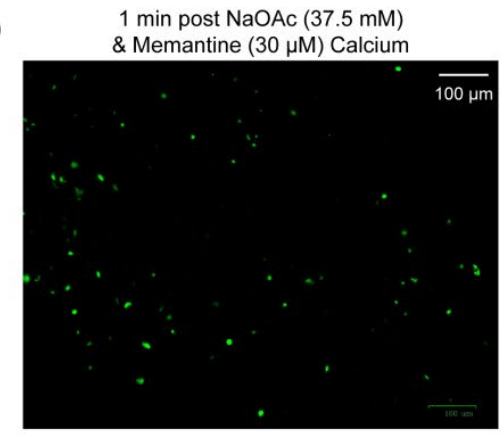

$\mathbf{E}$

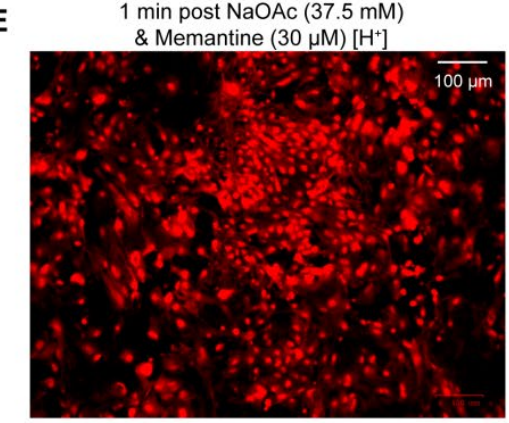

Merged Calcium/[H+ $\left.\mathrm{H}^{+}\right]$

$\mathbf{F}$

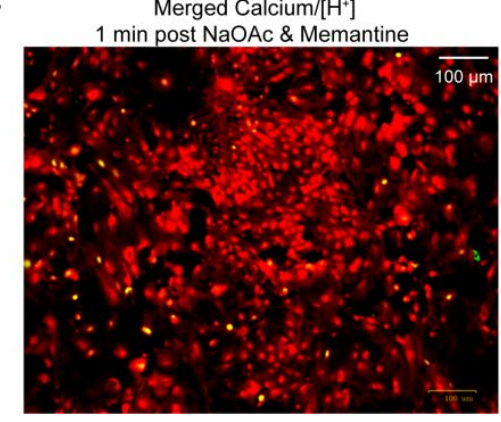

G

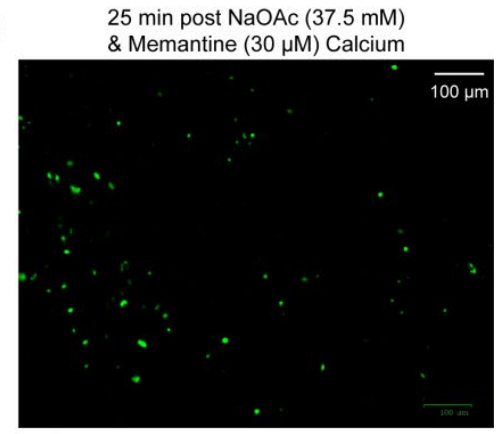

H

$25 \mathrm{~min}$ post $\mathrm{NaOAc}(37.5 \mathrm{mM})$ \& Memantine $(30 \mu \mathrm{M})\left[\mathrm{H}^{+}\right]$

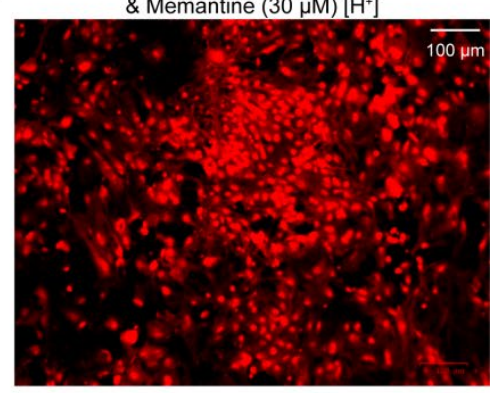

Merged Calcium/[H+]

I

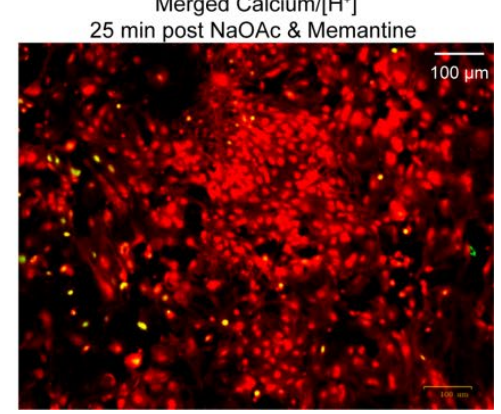

Fig 6. NMDAR blocker, memantine reduces acetate increase in cytosolic calcium but has no effect on acidification. (A) Baseline calcium fluorescence. (B) Baseline $\mathrm{pH}$ fluorescence, increased fluorescence indicates decreased pH. (C) Merged calcium and pH images. (D) 1 minute post $\mathrm{NaOAc} \&$ memantine, calcium fluorescence. (E) 1 min post NaOAc \& memantine, $\mathrm{pH}$ fluorescence. (F) Merged calcium and pH images from NaOAc \& memantine. (G) 25 minutes post NaOAc \& memantine, calcium fluorescence. (H) 25 minutes post NaOAc \& memantine, pH fluorescence. (I) 25 minutes post $\mathrm{NaOAc} \&$ memantine, merged calcium and $\mathrm{pH}$ images. 
A

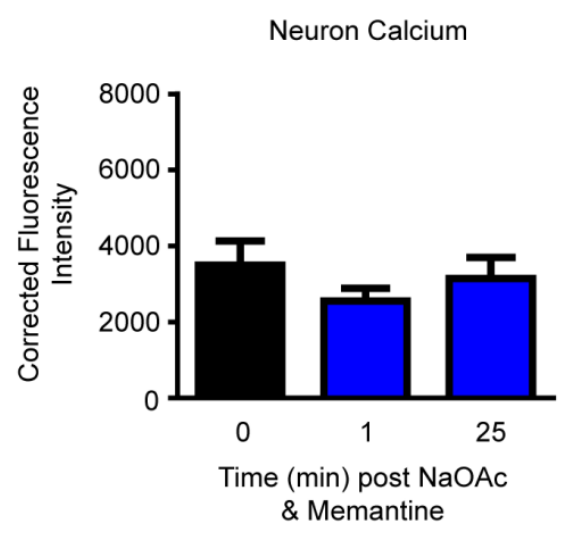

C

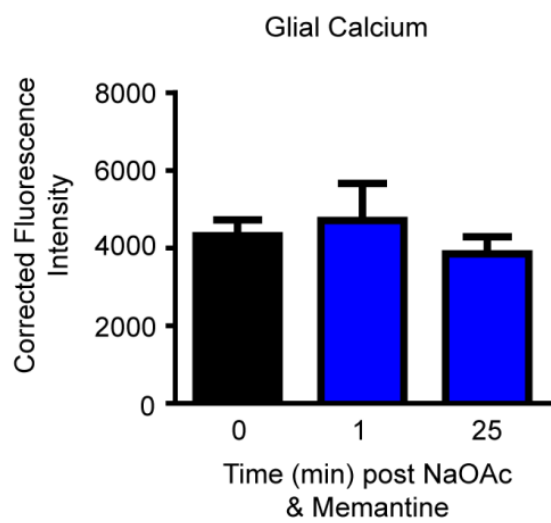

B

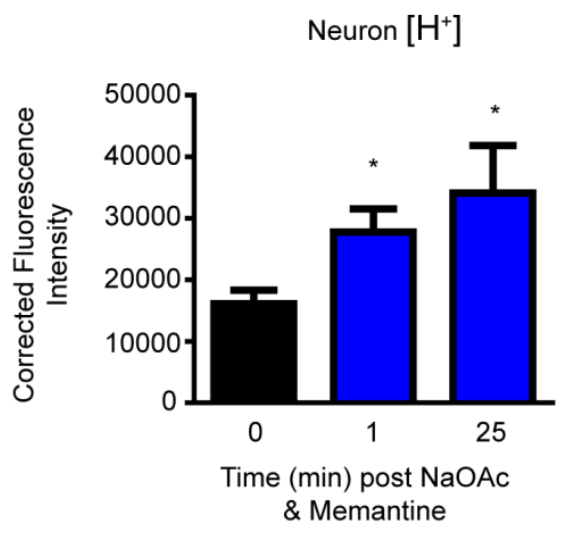

D

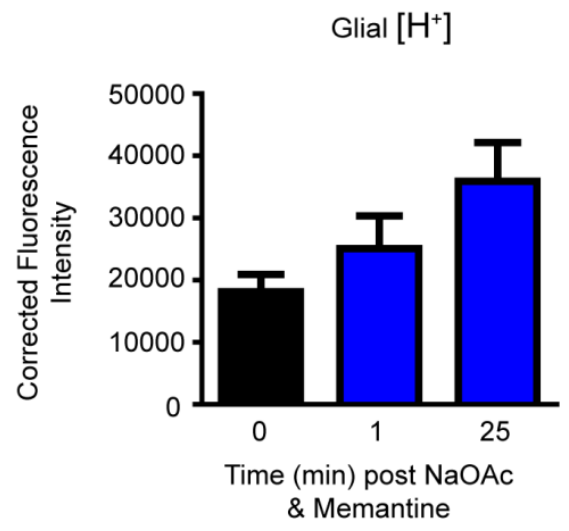

Fig 7. Summary data for image fluorescence intensity quantification from neurons and glial cells with acetate and memantine. (A) Neuronal calcium time course with NaOAc \& memantine. (B) Neuronal $\mathrm{pH}$ time course with $\mathrm{NaOAc} \&$ memantine $(* \mathrm{P}<0.05$ vs baseline). (C) Glial calcium time course with NaOAc \& memantine. (D) Glial pH time course with NaOAc \& memantine.

\section{Discussion}

To the best of our knowledge, there have been very limited publications regarding ethanol metabolism and the production of acetate, especially the effects of acetate on neuronal signaling. Carmichael published in 1991 and 1993 the effects of ethanol and acetate on adenosinergic signaling (Carmichael et al., 1991; Carmichael et al., 1993), and Phillips (Phillis et al., 1992) in 
1992 reported similar findings as Carmichael. Ethanol generated acetate effects on neuronal signaling was relatively silent until 2010 when Maxwell and colleagues reported that acetate was likely the cause of alcohol hangover in rats (Maxwell et al., 2010). Since that time, several groups have published reporting several findings regarding acetate derived from ethanol metabolism. Jiang and colleagues identified that acetate uptake and metabolism was enhanced in the brains of chronic ethanol users compared to non-heavy drinkers (Jiang et al., 2013) and Wang explored the effects of ethanol metabolism and generation of acetate utilization in the rat brain (Wang et al., 2013). To date, the general consensus among many ethanol researchers is that aceate is relatively non-toxic with only mild influences on neuronal function as per NIAAA (Zakhari, 2006). This notion however is contradicted by overwhelming evidence reported through the decades regarding the effects of acetate on neuronal signaling.

The recent investigation into gut microbes regulating neuronal function have revealed several interesting findings. The first is that diet, and gut microbiota can influence the production of several SCFA, primarily acetic acid/acetate, proprionic acid/proprionate and butyric acid/butyrate (Frost et al., 2014; Perry et al., 2016; Sampson et al., 2016). These SCFA have been found to increase; parasympathetic nerve activity, the release of both GABA and glutamate in the hypothalamus, and contribute to activated microglia and neuronal inflammation in a Parkinson's like animal model. Furthermore, Chen's study noted increases in spontaneous synaptic currents via NMDAR at developing neuromuscular synapses (Chen et al., 1998) and Drapeau's study found that acetate increased calcium and acidified dopaminergic neurons which facilitated the release of neurotransmitter via two distinct mechanisms (Drapeau and Nachshen, 1988). Likewise, hemodialysis studies which utilized acetate based solutions noted extreme vasodialation, flushing and intolerances (Amore et al., 1997; Bingel et al.); similar to those effects commonly associated 
with alcohol hangover and withdrawl symptoms. Thus as it would appear, there is a distinct disconnect between ethanol research and the effects of acetate on neuronal firing.

Given the fact that our data directly supports enhanced excitatory drive in CeA-RVLM neurons from acetate (Fig 2 \&5), increased calcium and neuronal acidification from acetate (Fig 3,4,6 \&7) and Drapeau's study demonstrating acetate facilitated release of dopamine (Drapeau and Nachshen, 1988); one may speculate that acetate may faciliate the release of multiple neurotransmitters depending on the phenotype of the neuron (graphical figure). Shifting the focus from ethanol or acetaldehyde to acetate, may be better suited to help explain the often complex and contradictory findings which have been noted in ethanol research. As mentioned previously, ethanol research established that acetate was found to increase adensosinergic signaling in neurons (Carmichael et al., 1993; Phillis et al., 1992). Manzoni and colleagues demonstrated that in CA1 hippocampal slices, NMDAR activation preceded adnosine release (Manzoni et al., 1994). Thus, their findings demonstrated that release of adenosine acted as an inhibitory break on CA1 neurons as a result of an excitatory stimulus which activated NMDAR. Our results would help explain the findings of Carmichael (Carmichael et al., 1991; Carmichael et al., 1993) and Phillips (Phillis et al., 1992) on acetate mediated adenosine release from ethanol. Acetate would activate a more upstream mechanism which requires acetate induced activation of NMDAR. Whether this finding is consistent remains to be discovered.

To summarize, we have demonstrated that ethanol metabolism to the SCFA, acetic acid/acetate increase serum, CSF and amygdala tissue acetate in a time dependent manner. Furthermore, we demonstrate that acetate activates NMDAR in vivo (Fig 1) and in vitro (Fig 2-7). The acetate induced increase in CeA excitability is capable of initiating a sympathoexcitatory response resulting in an increase in SNA, MAP and HR (Fig 1). Our results suggest that the ethanol 
induced increase in excitatory drive within the mammalian brain is likely not due to ethanol or acetaldehyde perse (Fig 1), rather the generation of the SCFA, acetic acid/acetate which modulates NMDAR from an external and internal component (Fig 2-7). These findings may provide key advances and novel insight for the ethanol research community as they persue mechanisms and treatment strageties for one of the most widely used recreational drug in the world.

\section{MATERIALS AND METHODS Animals}

Male Sprague-Dawley rats purchased from Charles River Labs (Wilmington, MA, USA) were individually housed in a temperature controlled room $\left(22-23{ }^{\circ} \mathrm{C}\right)$ with a $14 \mathrm{~h}: 10 \mathrm{~h}$ light-dark cycle. Chow and tap water were available ad libitum unless otherwise noted. All experimental and surgical procedures were carried out under the guidelines of the National Institutes of Health Guide for the Care and Use of Laboratory Animals with the approval of the Institutional Animal Care and Use Committee at Michigan Technological University.

\section{In vivo whole animal recordings of MAP, SSNA and LSNA}

Animal surgery was performed following the previously described protocol (Gui et al., 2012). On the day of the experiment, rats were anesthetized with an intraperitoneal injection containing a mixture of $\alpha$-chloralose $(80 \mathrm{mg} / \mathrm{kg})$ and urethane $(800 \mathrm{mg} / \mathrm{kg})$. Adequate depth of anesthesia was assessed before surgery by the absence of the pedal withdrawal reflex and corneal reflexes. Animals were instrumented with an arterial catheter inserted into the aorta through a femoral artery. The catheter was connected to a pressure transducer to measure arterial blood pressure. Heart rate (HR) was obtained from the R-wave of the electrocardiogram (ECG) (lead I). A catheter was also placed in the left femoral vein to administer drugs. After tracheal cannulation, 
rats were paralyzed with gallamine triethiodide $(25 \mathrm{mg} \cdot \mathrm{kg}-1 \cdot \mathrm{h}-1 \mathrm{iv})$ and artificially ventilated with oxygen-enriched room air. After paralysis, adequate depth of anesthesia was determined by lack of pressor responses to noxious foot pinch. Supplemental doses of anesthesia equal to $10 \%$ of the initial dose were given when needed. End-tidal $\mathrm{PCO}_{2}$ was continuously monitored and maintained within normal limits $(35-40 \mathrm{mmHg})$ by adjusting ventilation rate ( $80-100$ breaths/min) and/or tidal volume $(2.0-3.0 \mathrm{ml})$. Body temperature was held at $37^{\circ} \mathrm{C}$ with a water-circulating pad.

\section{Recording of sympathetic nerve activity}

Sympathetic nerve activity recording was performed according to previously described protocols(Chapp et al., 2014; Gui et al., 2012; Stocker and Muntzel, 2013). With the use of a left flank incision, a left lumbar and postganglionic splanchnic sympathetic nerve bundle was isolated from surrounding tissue and mounted on a stainless steel wire electrode $(0.127-\mathrm{mm}$ OD; A-M Systems), and covered with a silicon-based impression material (Coltene, Light Body) to insulate the recording from body fluids. The recorded signal was directed to an AC amplifier (P511; Grass Technologies) equipped with half-amplitude filters (band pass: 100-1,000 Hz) and a 60-Hz notch filter. The processed signal was rectified, integrated (10-ms time constant), and digitized at a frequency of 5,000 Hz using a $1401 \mathrm{Micro3}$ analog-to-digital converter and Spike 2 software (7.04 version; Cambridge Electronic Design, Cambridge, UK). The background noise was determined by a bolus injection of hexamethonium (30 mg/kg iv), a ganglionic blocker, at the end of the experiment and was subtracted from all the integrated values of sympathetic nerve activity.

\section{CeA microinjection}


CeA injections were performed as previously described(Chapp et al., 2014). Animals were placed in a stereotaxic head frame, and the skull was leveled between bregma and lambda. A section of skull was removed so that a single-barreled glass microinjector pipette could be lowered vertically into the CeA. The following stereotaxic coordinates were used: CeA, caudal to the bregma, $-2.4 \sim-2.5 \mathrm{~mm}$; lateral to the midline, $4.8 \sim 5.0 \mathrm{~mm}$; and ventral to the dura, $7.7 \sim 8.0$ $\mathrm{mm}$. All animals were allowed to stabilize at least $2 \mathrm{~h}$ following surgery. To test whether the ethanol metabolite acetate elicited a sympathoexcitatory response and whether activation of NMDA receptors was involved in these responses, the effects of CeA injection of acetate $(0.1$ $\mu \mathrm{mol}$ and $0.20 \mu \mathrm{mol})$ and a cocktail containing acetate $(0.20 \mu \mathrm{mol})$ and memantine $(3.0 \mathrm{nmol})$ were determined in separate groups of animals. All compounds were microinjected in a volume of $100 \mathrm{~nL}$ with a pneumatic pump (WPI). The volume of each injection was determined by measuring the movement of the fluid meniscus within the microinjector pipette using a dissecting microscope equipped with an eyepiece reticule. At the end of each experiment, Chicago blue dye solution (2\% in saline, $100 \mathrm{~nL}$ ) was injected into the CEA to mark the site of each injection. Brains were removed and post fixed for 5 days at room temperature in 4\% paraformaldehyde. Brain coronal sections containing the $\mathrm{CeA}$ were cut, and microinjection sites were identified under light microscopy. Rats with injection site(s) not inside the CeA were excluded from data analysis.

\section{Retrograde labeling}

Retrograde labeling of CeA-RVLM Neurons: Male Sprague-Dawely rats (350-450 g) were retrograde labeled from the RVLM to the CeA. Rats were anesthetized with an intraperitoneal injection (i.p.) of sodium pentobarbital $(50 \mathrm{mg} / \mathrm{kg})$, placed in a stereotaxic frame, leveled between bregma and lambda and the skull exposed with a midline incision. A small, unilateral burr hole 
was drilled to expose the cerebellum in the caudal section of the skull and a glass micropipette lowered into the pressor region of the RVLM (coordinates: $-12.7 \mathrm{~mm}$ caudal to bregma, $1.8 \mathrm{~mm}$ lateral to midline and $8.9 \mathrm{~mm}$ below the skull) (Chen and Toney, 2009). $150 \mathrm{~nL}$ fluospheres (Life Technologies) was injected into the RVLM using a pneumatic pump (WPI) and left in place for approximately 5 minutes to prevent tracer backflow. The midline incision was closed and the rats administered a subcutaneous (s.c.) injection of penicillin $\mathrm{G}(30,000$ units) and metacam (1 mg/kg, NSAID) in $0.5 \mathrm{~mL}$ saline for three days post-surgery to prevent infection and reduce pain.

\section{Whole-cell patch clamp recordings}

Five-seven days post labeling, rats were anesthetized with isoflurane $\left(3 \%\right.$ in $\left.\mathrm{O}_{2}\right)$ and decapitated. The brain was rapidly removed and chilled in ice cold cutting solution, containing (in $\mathrm{mM}$ ): 206 sucrose, $2 \mathrm{KCl}, 2 \mathrm{MgSO}_{4}, 1.25 \mathrm{NaH}_{2} \mathrm{PO}_{4}, 26 \mathrm{NaHCO}_{3}, 1 \mathrm{CaCl}_{2}, 1 \mathrm{MgCl}_{2}, 10$ d-glucose, and 0.4 ascorbic acid, osmolarity 295-302 mosmol L-1 measured with an osmometer (Wescor), $\mathrm{pH}$ 7.3-7.4, continuously gassed with $95: 5 \mathrm{CO}_{2}: \mathrm{O}_{2}$ to maintain $\mathrm{pH}$ and $\mathrm{pO}_{2}$. A brain block was cut including the CeA region and affixed to a vibrating microtome (Leica VT 1000S; Leica, Nussloch, Germany). Coronal sections of $250 \mu \mathrm{m}$ thickness were cut, and the slices transferred to a holding container of artificial cerebral spinal fluid (ACSF) maintained at $30^{\circ} \mathrm{C}$, continuously gassed with 95:5 $\mathrm{CO}_{2}: \mathrm{O}_{2}$, containing (in $\mathrm{mM}$ ): $125 \mathrm{NaCl}, 2 \mathrm{KCl}, 2 \mathrm{MgSO}_{4}, 1.25 \mathrm{NaH}_{2} \mathrm{PO}_{4}, 26 \mathrm{NaHCO}_{3}, 2$ $\mathrm{CaCl}_{2}, 10$ d-glucose, and 0.4 ascorbic acid (osmolality: 295-302 mosmol L ${ }^{-1}$; pH 7.3-7.4) and allowed to recover for $1 \mathrm{hr}$. Following recovery, slices were transferred to a glass-bottomed recording chamber and viewed through an upright microscope (E600FN, Nikon) equipped with DIC optics, epi-fluorescence, an infrared (IR) filter and an IR-sensitive video camera (C2400, Hamamatsu, Bridgewater, NJ). 
Slices transferred to the glass-bottomed recording chamber were continuously perfused with ACSF, gassed with 95:5 $\mathrm{CO}_{2}: \mathrm{O}_{2}$, maintained at $30{ }^{\circ} \mathrm{C}$ and circulated at a flow of $2 \mathrm{~mL} \mathrm{~min}^{-}$ 1. Patch electrodes were pulled (Flaming/Brown P-97, Sutter Instrument, Novato, CA) from borosilicate glass capillaries and polished to a tip resistance of 4-8 M 2 . Electrodes were filled with a solution containing (in mM) $135 \mathrm{~K}$-gluconate, $10 \mathrm{HEPES}, 0.1 \mathrm{EGTA}, 1.0 \mathrm{MgCl}_{2}, 1.0 \mathrm{NaCl}$, 2.0 $\mathrm{Na}_{2} \mathrm{ATP}$, and $0.5 \mathrm{Na}_{2}$ GTP (osmolality: 280-285 mosmol L ${ }^{-1}$; $\mathrm{pH}$ 7.3). For acetic acid loaded neurons, the same internal solution was prepared and 7-15 $\mathrm{mM}$ acetic acid added to adjust the $\mathrm{pH}$ to 5.2. Once a G $\Omega$ seal was obtained, slight suction was applied to break into whole-cell configuration and the cell allowed to stabilize which was determined by monitoring capacitance, membrane resistance, access resistance and resting membrane potential $\left(\mathrm{V}_{\mathrm{m}}\right)(\mathrm{Chen}$ and Toney, 2009). Records were not corrected for a liquid junction potential of $-15 \mathrm{mV}$. Cells that met the following criteria were included in the analysis: action potential amplitude $\geq 50 \mathrm{mV}$ from threshold to peak, input resistance $\left(R_{\text {input }}\right)>0.3 \mathrm{G} \Omega$ (determined by injection of $-20 \mathrm{pA}$ from a holding potential of $-80 \mathrm{mV}$ ), resting $V_{\mathrm{m}}$ negative to $-50 \mathrm{mV}$, and $<20 \%$ change in series resistance during the recording. Recordings were made using an Axopatch 200B amplifier and pCLAMP software (v10.2, Axon Instruments, Union City, CA). Signals were filtered at $1 \mathrm{kHz}$, digitized at $10 \mathrm{kHz}$ (Digidata 1400A, Axon Instruments), and saved on a computer for off-line analysis.

Effect of acetate on the excitability of CeA-RVLM neurons and the role of NMDA receptors (current-clamp): With $\mathrm{V}_{\mathrm{m}}$ adjusted to $-80 \mathrm{mV}$ by continuous negative current injection, a series of square-wave current injections was delivered in steps of $+25 \mathrm{pA}$, each for a duration of $800 \mathrm{~ms}$. To determine the action potential voltage threshold $(V \mathrm{t})$ and depolarizing $R_{\text {input }}$ below $V_{\mathrm{t}}$, ramp current injections $(0.2 \mathrm{pA} / \mathrm{ms}, 1,000 \mathrm{~ms})$ were made from a potential of $-80 \mathrm{mV}$. Squarewave and ramp current injections were made in the same neurons. Effects of acetate on neuronal 
excitability were determined by comparing current evoked spike frequency responses under control conditions with responses recorded from neurons exposed to bath application of acetate. To determine the dose-dependent response, the effect of various concentration of acetate $(0.0,7.5$, 37.5 and $75.0 \mathrm{mM}$ ) on the excitability was determined in separate groups of neurons, respectively. To test whether the activation of NMDA receptors was involved in the increased neuronal excitability elicited by acetate, the effect of bath application of memantine $(30 \mu \mathrm{M}$, NMDA receptor pore blocker), on the excitability was determined in the presence of acetate $(37.5 \mathrm{mM})$ in a separate group of neurons.

Acetate evoked inward current and the role of NMDA receptors (voltage-clamp) in CeARVLM neurons: Brain slices were continuously perfused with modified, $\mathrm{Mg}^{2+}$ free $\mathrm{ACSF}$ containing (in mM): $127 \mathrm{NaCl}, 2 \mathrm{KCl}, 1.25 \mathrm{NaH}_{2} \mathrm{PO}_{4}, 26 \mathrm{NaHCO}_{3}, 2 \mathrm{CaCl}_{2}, 10$ d-glucose, and 0.4 ascorbic acid (osmolality: 295-302 mosmol $\mathrm{L}^{-1}$; $\mathrm{pH}$ 7.3-7.4), gassed with 95:5 $\mathrm{CO}_{2}: \mathrm{O}_{2}$, maintained at $30{ }^{\circ} \mathrm{C}$ and circulated at a flow of $2 \mathrm{~mL} \mathrm{~min}^{-1}$. Tetrodotoxin (TTX, voltage gated sodium channel blocker, $0.5 \mu \mathrm{M}$ ) and picrotoxin (GABA-A blocker, $100 \mu \mathrm{M}$ ) were added into the circulating extracellular, $\mathrm{Mg}^{2+}$ free ACSF. Cells were voltage clamped at $\mathrm{V}_{\mathrm{m}}=-80 \mathrm{mV}$ and allowed to stabilize by monitoring baseline current. Once cells were stable and baseline recording in the absence of acetate $\sim 1.5$ min was observed, acetate $(37.5 \mathrm{mM})$ was added to the circulating bath and recorded until a plateau was observed $>15 \mathrm{~min}$. At this point, washout and recovery was observed. To test whether the activation of NMDA receptors is involved in the inward current evoked by acetate, the effect of memantine $(30 \mu \mathrm{M})$ on the inward current was determined. In a separate group of neurons, the co-application of acetate $(37.5 \mathrm{mM})$ and memantine $(30 \mu \mathrm{M})$ was applied into the circulating bath and the inward current was observed. To exclude the possibility that the inward current evoked by sodium acetate was due to the increases in extracellular sodium 
concentration, equimolar sodium gluconate $(37.5 \mathrm{mM})$ was substituted for sodium acetate and the inward current was recorded.

Note that current- and voltage-clamp recordings were made from different groups of CeARVLM neurons.

\section{Preparation of neuronal cultures}

Whole brain neuronal cultures were made from 1 day old SD rats according to our previous publication(Shan et al., 2010). Briefly, rats were anesthetized with pentobartibal $(50 \mathrm{mg} / \mathrm{kg})$ and the brains extracted, dissected, combined, brain cells dissociated and cells plated on poly-L-lysine precoated culture dishes. Two days following plating, cultures were treated for two days with cytosine arabanoside (ARC, $10 \mu \mathrm{M})$ to kill off rapidly dividing cells (astroglial and astrocytes) followed by fresh ARC free media for the remainder of cultures. Neuronal cultures contained $>$ $90 \%$ neurons with the remainder primarily astroglial. Neuronal cell cultures were grown for 10-14 days before use in cell culture experiments.

\section{Real-time calcium and $\mathrm{pH}$ imaging}

Primary neuronal cultures 12-14 days post isolation were incubated for 30 min with Fluo4AM (Thermofisher, $3 \mu \mathrm{M}$ final concentration) and pHrodo Red AM according to the manufactures instructions in artificial cerebral spinal fluid (ACSF), containing (in mM): $125 \mathrm{NaCl}$, $2 \mathrm{KCl}, 2 \mathrm{MgSO}_{4}, 1.25 \mathrm{NaH}_{2} \mathrm{PO}_{4}, 26 \mathrm{NaHCO}_{3}, 2 \mathrm{CaCl}_{2}, 10$ d-glucose, and 0.4 ascorbic acid (osmolality: 295-302 mosmol L ${ }^{-1}$; $\mathrm{pH} 7.3-7.4$ ) in a 5\% $\mathrm{CO}_{2}$ humidified incubator at $37^{\circ} \mathrm{C}$. The staining solution was aspirated and fresh ACSF $(0.5 \mathrm{~mL})$ added to the cells. Baseline calcium and $\mathrm{pH}$ images were taken followed by the addition of acetate and/or acetate and memantine in ACSF 
(0.5 mL additional volume added) to reach the desired concentrations (ie, $0.5 \mathrm{~mL}$ ACSF initial, then add $0.5 \mathrm{~mL}$ acetate $(75 \mathrm{mM})$ in ACSF. Final concentration acetate $(37.5 \mathrm{mM}))$. Images were captured for each well in a 24 well plate using a cell imager equipped with the correct LED lights (ZOE, Bio-Rad). Fluorescence intensity was analyzed and quantified using ImageJ software (Schneider et al., 2012) on 6 randomly selected cells for each treatment and corrected fluorescence intensity (CFIT) compared between treatment groups prior to adjusting backgrounds. CFIT was calculated based on individual background fluorescence within each well, prior to batch background normalization for image preparation. Duplicates of each treatment were compared and all showed similar trends. Negative controls were run for ACSF alone on time course for alterations in baseline calcium or $\mathrm{pH}$ and there was no significant change in baseline values compared to 25 minutes post ACSF only.

\section{Ethanol and glucose administration}

Rats were randomly divided into two groups and given an intraperitoneal injection (I.P.) of either EtOH $(2 \mathrm{~g} / \mathrm{kg}) 2 \mathrm{~mL}$ volume total, or an equal caloric/volume of glucose. Rats were returned to their cages and allowed time for metabolism (1, 4 and $24 \mathrm{hrs})$. Following metabolism, rats were deeply anesthetized with sodium pentobarbital $(50 \mathrm{mg} / \mathrm{kg})$ and cerebrospinal fluid was collected through a needle puncture in the cisterna magna as previously described (Nirogi et al., 2009). Then, venous blood was taken through a right ventricle draw. The brain was rapidly removed and a sample of tissue from the amygdala was placed into separate $1.5 \mathrm{~mL}$ centrifuge tubes and flash frozen in liquid nitrogen. Blood samples were centrifuged at 13,000 rcf for $10 \mathrm{~min}$ and the serum was removed to a fresh $1.5 \mathrm{~mL}$ centrifuge tube. All samples were then stored in a $-80{ }^{\circ} \mathrm{C}$ freezer until analysis by ion chromatography. 


\section{Ion Chromatography Sample Preparation}

For tissue samples; samples were thawed to room temperature and the centrifuge tube containing the tissue was weighed on an analytical balance before and after extraction according to our previous publication (Chapp et al., 2018). Tubes after extraction were washed with water, followed by ethanol (70\%) and allowed to completely dry before weighing. For the extraction, 100 $\mu \mathrm{L}$ of $\mathrm{ddH}_{2} \mathrm{O}(>18 \mathrm{M} \Omega)$ was added to the tube and the tissue was sonicated in pulses of 5 seconds at $20 \mathrm{kHz}$ for a total of 20-60 seconds or until the tissue was well homogenized. Tissue samples were centrifuged at 12,000 RPM for 10 minutes and the supernatant was removed to a fresh 1.5 $\mathrm{mL}$ centrifuge tube. The liquid sample extracts were then diluted 1000 fold by adding $10 \mu \mathrm{L}$ liquid sample to $9.990 \mathrm{~mL}$ of $\mathrm{ddH}_{2} \mathrm{O}(>18 \mathrm{M} \Omega)$ in sterile $15 \mathrm{~mL}$ centrifuge tubes. Liquid samples of CSF and serum were diluted 1000 fold for ion chromatography by adding $10 \mu \mathrm{L}$ liquid sample to 9.990 $\mathrm{mL}$ of $\mathrm{ddH}_{2} \mathrm{O}(>18 \mathrm{M} \Omega)$ in sterile $15 \mathrm{~mL}$ centrifuge tubes. All diluted samples were filtered through pre-flushed $\left(3 \mathrm{X}, \mathrm{ddH}_{2} \mathrm{O},>18 \mathrm{M} \Omega\right)$ sterile PTFE syringe filters $(0.2 \mu \mathrm{m})$ and sterile $3 \mathrm{~mL}$ disposable syringes (BD) into new, sterile $15 \mathrm{~mL}$ centrifuge tubes. The samples were transferred to ion chromatography vials $(5 \mathrm{~mL}$, Thermofisher) and analyzed via ion chromatography (Dionex ICS-2100).

\section{Acetate Measurements, IC}

Diluted and filtered samples were added to individual sample poly vials $(5 \mathrm{~mL}$, Thermofisher) and loaded into a Dionex AS-DV autosampler (Thermofisher). $0.5 \mathrm{~mL}$ from the poly vial was then passed to the IC system. For anions, the Dionex 2100 was equipped with a Dionex EGC III KOH RFIC, potassium hydroxide (KOH) eluent generator cartridge 
(Thermofisher) and an AS17-C 4mm analytical and guard column set. Water ( $>18 \mathrm{M} \Omega$ ) used for generating the eluent was sonicated for 20 minutes followed by degassing with nitrogen for an additional 10 minutes prior to IC. The sample was eluted with $\mathrm{KOH}$ using the following method. -5-0 minutes: Equilibration at $1 \mathrm{mM} \mathrm{KOH}$

0 - 5 minutes: Isocratic at $1 \mathrm{mM} \mathrm{KOH}$

5 - 15 minutes: Ramp, $1 \mathrm{mM}$ to $30 \mathrm{mM} \mathrm{KOH}$

15 - 20 minutes: Ramp, $30 \mathrm{mM}$ to $40 \mathrm{mM} \mathrm{KOH}$

To determine the acetate concentration from the samples, a standard curve was constructed for known concentrations of acetate and a linear regression line was used from the areas under the curve for the known concentrations of acetate. Unknown sample acetate concentrations were determined based off the linear fit and then back calculated based on the 1000 fold dilution. For tissue samples, the concentration obtained from the linear fit was back calculated for the 1000 fold dilution, converted from concentration to moles and then divided by the tissue sample weight in volume to give the final tissue concentration.

\section{Chemicals}

All chemicals were obtained from Sigma-Aldrich (St Louis, MO, USA) with the exception of tetrodotoxin (Tocris Bioscience, UK) and tetraethylammonium sodium (Fluka BioChemika, Switzerland). Glacial acetic acid was obtained from Sigma-Aldrich (St. Louis, MO) and ultra-pure water $(>18 \mathrm{M} \Omega$ ) obtained in-house by filtration and purification of house distilled water from an EasyPure II water filtration system (Barnstead). Methanesulfonic acid (Acros Organics) and anion and cation standards were obtained from ThermoScientific. 


\section{Statistical analysis}

Data values were reported as mean \pm SE. Depending on the experiments, group means were compared using either chi-squared test, paired, unpaired Student's $t$-test, a one-way or a twoway ANOVA. Differences between means were considered significant at $\mathrm{P}<0.05$. Where differences were found, Bonferroni post hoc tests were used for multiple pair-wise comparisons. All statistical analyses were performed with a commercially available statistical package (GraphPad Prism, version 5.0).

\section{SUPPLEMENTAL FIGURES AND TABLES}


$\mathrm{N}=3$ Glucose, EtOH $4 \mathrm{hr} \& \mathrm{EtOH} 24 \mathrm{hr}$ $\mathrm{N}=4 \mathrm{EtOH} 1 \mathrm{hr}$

A

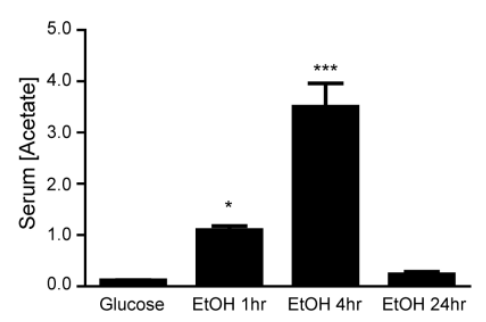

B

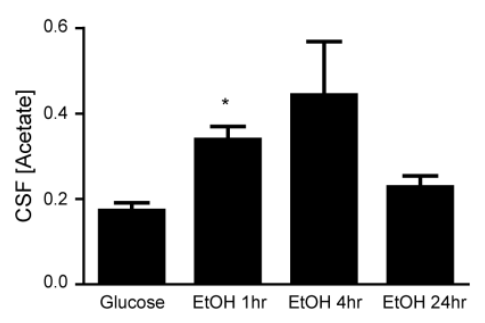

C

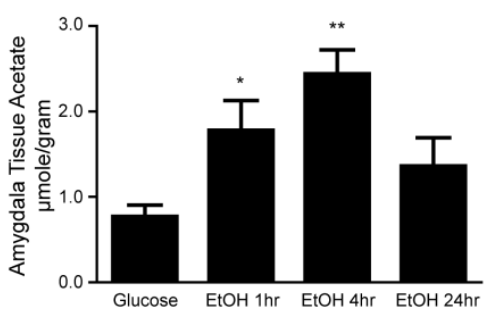

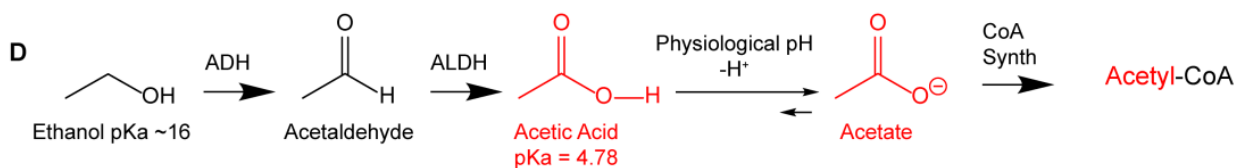

Supplemental Fig 1S. Ethanol metabolism increases serum, CSF and amygdala acetate in a time

dependent manner. (A) Serum acetate at 1, 4 and $24 \mathrm{hrs}$ post ethanol ( $2 \mathrm{~g} / \mathrm{kg}$, I.P.). Peak acetate was found at 4 hrs post ethanol $(3.51 \pm 0.45 \mathrm{mM})$. (B) CSF acetate increased in a time dependent manner with peak acetate at $4 \mathrm{hrs}$ post ethanol $(0.44 \pm 0.12 \mathrm{mM})$. (C) Amygdala tissue acetate increased in a time dependent manner with peak acetate at $4 \mathrm{hrs}$ post ethanol $(2.44 \pm 0.27 \mu \mathrm{mole} / \mathrm{g})$. (D) Major metabolic pathway for the metabolism of ethanol. Ethanol is metabolized via alcohol dehydrogenase (ADH) to acetaldehyde, which undergoes rapid conversion via aldehyde dehydrogenase (ALDH) to acetic acid. pKa values are a measure of relative acidities of hydrogen atoms, the lower the $\mathrm{pKa}$ value, the more acidic the hydrogen atom. At physiological $\mathrm{pH}$, ethanol does not lose a proton; however, acetic acid is deprotonated generating its conjugate base, acetate. Acetate directly feeds into the citric acid cycle via coupling of acetate with coenzyme A via the enzyme acetyl-CoA synthetase (CoA Synth).

\section{Supplemental Table 1S. Membrane properties of CeA-RVLM neurons}


bioRxiv preprint doi: https://doi.org/10.1101/2020.07.20.212597; this version posted July 22, 2020. The copyright holder for this preprint (which was not certified by peer review) is the author/funder. All rights reserved. No reuse allowed without permission.

Table 1 Membrane Properties of CeA-RVLM neurons

\begin{tabular}{cccccc}
\hline Group & $\mathbf{n}$ & $\begin{array}{c}\mathrm{V}_{\mathrm{m}} \\
(\mathrm{mV})\end{array}$ & $\begin{array}{c}\mathrm{C}_{\mathrm{m}} \\
(\mathrm{pF})\end{array}$ & $\begin{array}{c}\mathrm{HR}_{\text {input }} \\
(\mathrm{G} \Omega)\end{array}$ & $\begin{array}{c}\mathrm{V}_{\mathrm{t}} \\
(\mathrm{mV})\end{array}$ \\
\hline Control & 7 & $-58.0 \pm 3.0$ & $47.4 \pm 2.5$ & $0.47 \pm 0.07$ & $-43.8 \pm 1.8$ \\
$\mathrm{NaOAc}(7.5 \mathrm{mM})$ & 6 & $-58.5 \pm 2.6$ & $45.3 \pm 4.5$ & $0.52 \pm 0.08$ & $-42.4 \pm 2.7$ \\
$\mathrm{NaOAc}(37.5 \mathrm{mM})$ & 8 & $-62.3 \pm 2.2$ & $34.6 \pm 2.5$ & $0.58 \pm 0.03$ & $-49.3 \pm 1.8$ \\
$\begin{array}{c}\mathrm{NaOAc}(37.5 \mathrm{mM}) \\
\& \text { AP5 }\end{array}$ & 6 & $-67.9 \pm 4.3$ & $36.3 \pm 2.0$ & $0.45 \pm 0.07$ & $-45.0 \pm 2.5$ \\
$\mathrm{NaOAc}(37.5 \mathrm{mM})$ & 6 & $-63.0 \pm 3.4$ & $39.0 \pm 3.5$ & $0.54 \pm 0.10$ & $-47.5 \pm 1.7$ \\
$\begin{array}{c}\text { \& memantine } \\
\mathrm{NaOAc}(75 \mathrm{mM})\end{array}$ & 7 & $-59.9 \pm 1.8$ & $42.2 \pm 1.6$ & $0.40 \pm 0.04$ & $-47.7 \pm 1.1$ \\
$\begin{array}{c}\mathrm{HOAc} \mathrm{pH}=(5.20) \\
\mathrm{HOAc} \mathrm{pH}=(5.20) \\
\& \mathrm{Mem}(30 \mu \mathrm{M})\end{array}$ & 6 & $-63.0 \pm 2.0$ & $39.5 \pm 1.9$ & $0.54 \pm 0.09$ & $-49.3 \pm 1.4$ \\
\hline
\end{tabular}

Values are mean $\pm S E, n=$ number of neurons, $V_{m}$, resting membrane potential; $C_{m}$, membrane capacitance; $H R_{\text {input }}$, hyperpolarizing input resistance; $V_{t}$, sub-threshold of membrane potential to fire action potential, $\mathrm{NaOAc}=$ acetate, $\mathrm{HOAc}=$ acetic acid 
A

1) $5 \% \mathrm{v} / v \mathrm{EtOH}=\frac{5 \mathrm{mLEtOH}}{100 \mathrm{~mL}} * 354.9 \mathrm{~mL}=17.75 \mathrm{~mL}$ EtOH
2) $17.75 \mathrm{~mL} \mathrm{EtOH} * \frac{0.78 \mathrm{~g} \mathrm{EtOH}}{1 \mathrm{mLEtOH}} * \frac{\text { mole EtOH }}{46.07 \mathrm{~g}}=0.30 \mathrm{moles} \mathrm{EtOH}$
3) 0.30 moles EtOH $* \frac{\text { mole HOAc }}{\text { mole EtOH }} \frac{60.05 \mathrm{~g} \mathrm{HOAc}}{\mathrm{mole} \mathrm{HOAc}} * \frac{1 \mathrm{~mL} \mathrm{HOAc}}{1.05 \mathrm{~g} \mathrm{HOAc}}=17.20 \mathrm{~mL} \mathrm{HOAc}$
$\frac{17.20 \mathrm{~mL} \mathrm{HOAc}}{354.9 \mathrm{~mL}} * 100=4.84 \% \mathrm{v} / \mathrm{v} \mathrm{HOAc}$
B

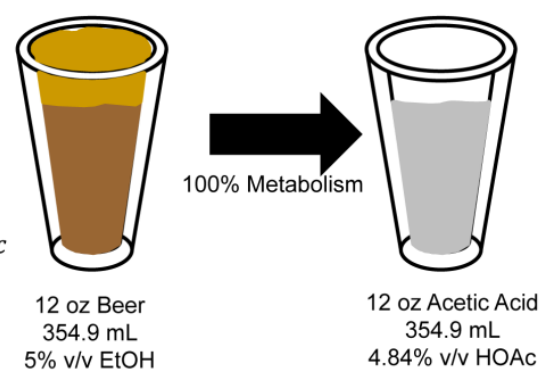

C

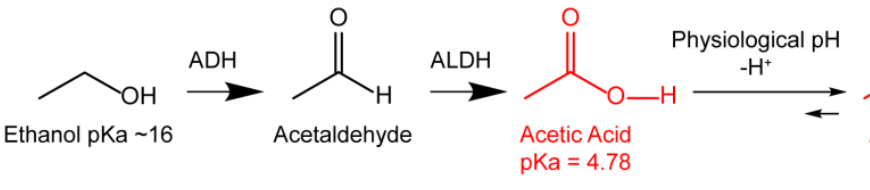

D

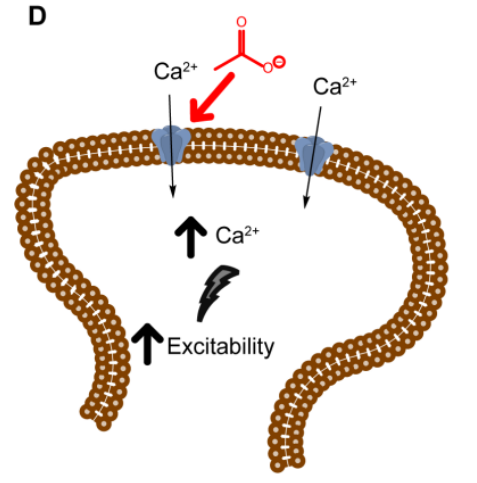

E

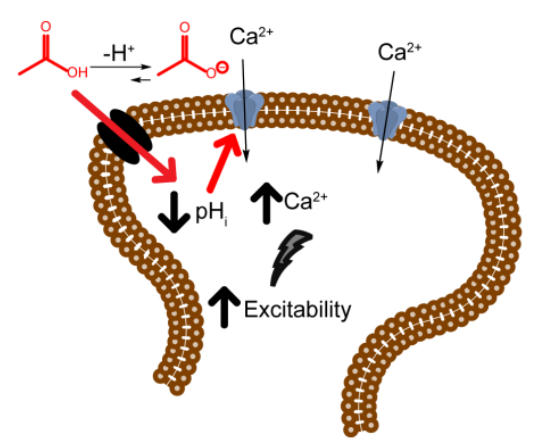

$\mathbf{F}$

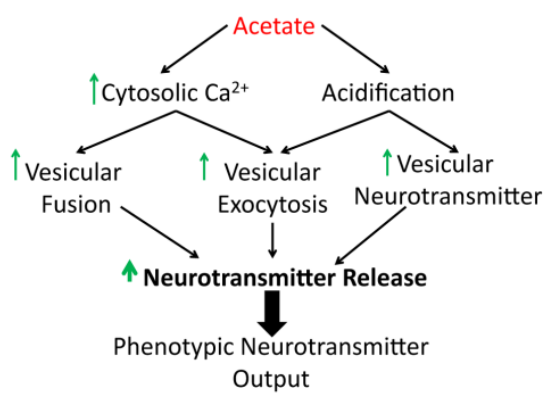

NMDAR

MCT

Graphical Figure. (A) Relative amount of HOAc/-OAc produced from $12 \mathrm{oz}(354.9 \mathrm{~mL})$ of beer at $5 \% \mathrm{v} / \mathrm{v} .1$ ) Conversion of $5 \% \mathrm{v} / \mathrm{v}$ to equivalent amount of pure $\mathrm{EtOH}$ in $354.9 \mathrm{~mL}$ total volume of beer. 2) Conversion of $\mathrm{EtOH}$ to moles of $\mathrm{EtOH}$. 3) Conversion of moles of $\mathrm{EtOH}$ to $\mathrm{mL}$ of pure HOAc. 4) $\% \mathrm{v} / \mathrm{v}$ of $\mathrm{HOAc} / \mathrm{OAc}$ generated per $354.9 \mathrm{~mL}$ of $5 \% \mathrm{v} / \mathrm{v}$ EtOH. (B) Pictoral respresentation of what one $12 \mathrm{oz}$ beer represents in terms of distilled white vinegar.

(C) Metabolic pathway for ethanol (EtOH) metabolism to $\mathrm{HOAc} / \mathrm{OAc}$. EtOH is metabolized by alcohol dehydrogenase (ADH) to acetaldehyde which is rapidly converted to HOAc (red) by aldehyde dehydrogenase (ALDH). At physiological pH, HOAc is deprotonated and exists primarly 
as ${ }^{-}$OAc. Ethanol itself is an exogenous source of a proton following oxidation. (D) External acetate activates NMDAR, increasing cytosolic calcium and increasing neuronal excitability. (E) External acetate is protonated generating acetic acid which is transported across the membrane by the monocarboxylate transporter, acidifying the neuron and activating NMDAR. This also leads to increased cytosolic calcium and increased neuronal excitability. (F) Proposed mechanisms as it relates to alcohol use disorders and SCFA regulation of neuronal function. The SCFA, acetate increases cytosolic calcium at least partially through NMDAR activation. Acetate also acidifies neurons which affects NMDAR gating. Acidification increases vesicular neurotransmitter concentrations based on proton gradients. Rises in intracellular calcium and acidification can govern the release of neurotransmitters and can therefore modulate the release of many neurotransmitters depending on the phenotypic output of the neuron (i.e., GABA, glutamate, dopamine, etc.).

\section{Authors' Contribution:}

A.D.C., M.J.H., K.M.D., J.E.B., R.A.L. and S.S. performed experiments. A.D.C., M.J.H., R.A.L., S.S., Z.S., L.Z. and Q.H.C. analyzed data. A.D.C., Q.H.C. and L.Z. prepared figures. A.D.C., Q.H.C. and L.Z. drafted the manuscript. All authors edited and revised manuscript. All authors approved the final version of the manuscript. A.D.C. and Q.H.C. conceptualized and designed the research.

\section{Acknowledgements:}

We would like to thank Dr. Lynn Mazzoleni for the help and use with the I.C., Dr. Timothy W. Chapp for his helpful suggestions and proof reading, Scott M. Chapp for proof reading and suggestions as well as Drs. Joe Erlichman and Ana Estevez for their early suggestions. We 
gratefully acknowledge Mingjun Gu for excellent technical assistance. This study was supported by: HL122952, HL145655, HL1292, AHA 16PRE27780121. Michigan Technological University Research Excellence Fund and Portage Health Foundation Research Excellence Fund. 


\section{REFERENCES}

Alaux-Cantin, S., Buttolo, R., Houchi, H., Jeanblanc, J., and Naassila, M. (2014). Memantine reduces alcohol drinking but not relapse in alcohol-dependent rats. Addiction biology.

Amore, A., Cirina, P., Mitola, S., Peruzzi, L., Bonaudo, R., Gianoglio, B., and Coppo, R. (1997). Acetate intolerance is mediated by enhanced synthesis of nitric oxide by endothelial cells. Journal of the American Society of Nephrology: JASN 8, 1431-1436.

Bingel, M., Koch, K., Lonnemann, G., Dinarello, C., and Shaldon, S. Enhancement of in-vitro human interleukin-1 production by sodium acetate. The Lancet 329, 14-16.

Boileau, I., Assaad, J.-M., Pihl, R.O., Benkelfat, C., Leyton, M., Diksic, M., Tremblay, R.E., and Dagher, A. (2003). Alcohol promotes dopamine release in the human nucleus accumbens. Synapse 49, 226-231.

Brodie, M.S., Pesold, C., and Appel, S.B. (1999). Ethanol directly excites dopaminergic ventral tegmental area reward neurons. Alcoholism, clinical and experimental research 23, 1848-1852.

Carmichael, F.J., Israel, Y., Crawford, M., Minhas, K., Saldivia, V., Sandrin, S., Campisi, P., and Orrego, H. (1991). Central nervous system effects of acetate: contribution to the central effects of ethanol. Journal of Pharmacology and Experimental Therapeutics 259, 403-408.

Carmichael, F.J., Orrego, H., and Israel, Y. (1993). Acetate-induced adenosine mediated effects of ethanol. Alcohol and alcoholism (Oxford, Oxfordshire) Supplement 2, 411-418.

Carter, J.R., Stream, S.F., Durocher, J.J., and Larson, R.A. (2011). Influence of acute alcohol ingestion on sympathetic neural responses to orthostatic stress in humans. American Journal of Physiology - Endocrinology And Metabolism 300, E771-E778. 
Chapp, A.D., Gui, L., Huber, M.J., Liu, J., Larson, R.A., Zhu, J., Carter, J.R., and Chen, Q.H. (2014). Sympathoexcitation and pressor responses induced by ethanol in the central nucleus of amygdala involves activation of NMDA receptors in rats. American journal of physiology Heart and circulatory physiology 307, H701-709.

Chapp, A.D., Schum, S., Behnke, J.E., Hahka, T., Huber, M.J., Jiang, E., Larson, R.A., Shan, Z., and Chen, Q.H. (2018). Measurement of cations, anions, and acetate in serum, urine, cerebrospinal fluid, and tissue by ion chromatography. Physiological reports 6, e13666.

Chen, Q.-H., and Toney, G.M. (2009). Excitability of paraventricular nucleus neurones that project to the rostral ventrolateral medulla is regulated by small-conductance $\mathrm{Ca} 2+$-activated $\mathrm{K}+$ channels. The Journal of Physiology 587, 4235-4247.

Chen, Q.-H., and Toney, G.M. (2010). In Vivo Discharge Properties of Hypothalamic Paraventricular Nucleus Neurons With Axonal Projections to the Rostral Ventrolateral Medulla. Journal of Neurophysiology 103, 4-15.

Chen, Y.H., Wu, M.L., and Fu, W.M. (1998). Regulation of presynaptic NMDA responses by external and intracellular $\mathrm{pH}$ changes at developing neuromuscular synapses. The Journal of neuroscience : the official journal of the Society for Neuroscience 18, 2982-2990.

Demaster, E.G., Nagasawa, H.T., and Shirota, F.N. (1983). Metabolic activation of cyanamide to an inhibitor of aldehyde dehydrogenase in vitro. Pharmacology, biochemistry, and behavior 18 Suppl 1, 273-277.

Drapeau, P., and Nachshen, D.A. (1988). Effects of lowering extracellular and cytosolic pH on calcium fluxes, cytosolic calcium levels, and transmitter release in presynaptic nerve terminals isolated from rat brain. The Journal of general physiology 91, 305-315. 
Frost, G., Sleeth, M.L., Sahuri-Arisoylu, M., Lizarbe, B., Cerdan, S., Brody, L., Anastasovska, J., Ghourab, S., Hankir, M., Zhang, S., et al. (2014). The short-chain fatty acid acetate reduces appetite via a central homeostatic mechanism. Nat Commun 5.

Gottfried, J.A., and Chesler, M. (1994). Endogenous H+ modulation of NMDA receptor-mediated EPSCs revealed by carbonic anhydrase inhibition in rat hippocampus. The Journal of Physiology $478,373-378$.

Grover, C.A., Frye, G.D., and Griffith, W.H. (1994). Acute tolerance to ethanol inhibition of NMDA-mediated EPSPs in the CA1 region of the rat hippocampus. Brain Research 642, 70-76.

Gui, L., LaGrange, L.P., Larson, R.A., Gu, M., Zhu, J., and Chen, Q.H. (2012). Role of small conductance calcium-activated potassium channels expressed in PVN in regulating sympathetic nerve activity and arterial blood pressure in rats. American journal of physiology Regulatory, integrative and comparative physiology 303, R301-310.

Hellstrom, E., and Tottmar, O. (1982). Acute effects of ethanol and acetaldehyde on blood pressure and heart rate in disulfiram-treated and control rats. Pharmacology, biochemistry, and behavior 17, 1103-1109.

Hicklin, T.R., Wu, P.H., Radcliffe, R.A., Freund, R.K., Goebel-Goody, S.M., Correa, P.R., Proctor, W.R., Lombroso, P.J., and Browning, M.D. (2011). Alcohol inhibition of the NMDA receptor function, long-term potentiation, and fear learning requires striatal-enriched protein tyrosine phosphatase. Proceedings of the National Academy of Sciences 108, 6650-6655.

Idrus, N.M., McGough, N.N., Riley, E.P., and Thomas, J.D. (2014). Administration of memantine during withdrawal mitigates overactivity and spatial learning impairments associated with neonatal alcohol exposure in rats. Alcoholism, clinical and experimental research 38, 529-537. 
Jiang, L., Gulanski, B.I., De Feyter, H.M., Weinzimer, S.A., Pittman, B., Guidone, E., Koretski, J., Harman, S., Petrakis, I.L., Krystal, J.H., et al. (2013). Increased brain uptake and oxidation of acetate in heavy drinkers. The Journal of Clinical Investigation 123, 1605-1614.

Kalaitzidis, R. (2015). Metabolic Abnormalities in Alcoholic Patients: Focus on Acid Base and Electrolyte Disorders, Vol 03.

Karadayian, A.G., Malanga, G., Czerniczyniec, A., Lombardi, P., Bustamante, J., and LoresArnaiz, S. (2017). Free radical production and antioxidant status in brain cortex non-synaptic mitochondria and synaptosomes at alcohol hangover onset. Free radical biology \& medicine 108 , $692-703$.

Karkhanis, A.N., Huggins, K.N., Rose, J.H., and Jones, S.R. (2016). Switch from excitatory to inhibitory actions of ethanol on dopamine levels after chronic exposure: Role of kappa opioid receptors. Neuropharmacology 110, 190-197.

Lin, J.C., Tsao, W.L., and Wang, Y. (1995). Cardiovascular effects of NMDA in the RVLM of spontaneously hypertensive rats. Brain Research Bulletin 37, 289-294.

Lovinger, D., White, G., and Weight, F. (1990). NMDA receptor-mediated synaptic excitation selectively inhibited by ethanol in hippocampal slice from adult rat. The Journal of Neuroscience $10,1372-1379$.

Lovinger, D.M., White, G., and Weight, F.F. (1989). Ethanol inhibits NMDA-activated ion current in hippocampal neurons. Science 243, 1721-1724.

Mameli, M., Zamudio, P.A., Carta, M., and Valenzuela, C.F. (2005). Developmentally regulated actions of alcohol on hippocampal glutamatergic transmission. The Journal of neuroscience : the official journal of the Society for Neuroscience 25, 8027-8036. 
Manzoni, O.J., Manabe, T., and Nicoll, R.A. (1994). Release of adenosine by activation of NMDA receptors in the hippocampus. Science 265, 2098-2101.

Mascia, M.P., Mihic, S.J., Valenzuela, C.F., Schofield, P.R., and Harris, R.A. (1996). A single amino acid determines differences in ethanol actions on strychnine-sensitive glycine receptors. Molecular pharmacology 50, 402-406.

Maxwell, C.R., Spangenberg, R.J., Hoek, J.B., Silberstein, S.D., and Oshinsky, M.L. (2010). Acetate Causes Alcohol Hangover Headache in Rats. PLoS ONE 5, e15963.

Mihic, S.J., Ye, Q., Wick, M.J., Koltchine, V.V., Krasowski, M.D., Finn, S.E., Mascia, M.P., Valenzuela, C.F., Hanson, K.K., Greenblatt, E.P., et al. (1997). Sites of alcohol and volatile anaesthetic action on GABAA and glycine receptors. Nature 389, 385-389.

Nirogi, R., Kandikere, V., Mudigonda, K., Bhyrapuneni, G., Muddana, N., Saralaya, R., and Benade, V. (2009). A simple and rapid method to collect the cerebrospinal fluid of rats and its application for the assessment of drug penetration into the central nervous system. Journal of neuroscience methods $178,116-119$.

Parsons, C.G., Gruner, R., Rozental, J., Millar, J., and Lodge, D. (1993). Patch clamp studies on the kinetics and selectivity of N-methyl-D-aspartate receptor antagonism by memantine (1-amino3,5-dimethyladamantan). Neuropharmacology 32, 1337-1350.

Perry, R.J., Peng, L., Barry, N.A., Cline, G.W., Zhang, D., Cardone, R.L., Petersen, K.F., Kibbey, R.G., Goodman, A.L., and Shulman, G.I. (2016). Acetate mediates a microbiome-brain-beta-cell axis to promote metabolic syndrome. Nature 534, 213-217.

Phillis, J.W., O'Regan, M.H., and Perkins, L.M. (1992). Actions of ethanol and acetate on rat cortical neurons: Ethanol/adenosine interactions. Alcohol 9, 541-546. 
Randin, D., Vollenweider, P., Tappy, L., Jéquier, E., Nicod, P., and Scherrer, U. (1995). Suppression of Alcohol-Induced Hypertension by Dexamethasone. New England Journal of Medicine 332, 1733-1738.

Roh, M.S., Cui, F.J., Kim, H.K., and Kang, U.G. (2011). Regulation of NMDA receptor subunits after acute ethanol treatment in rat brain. Alcohol and alcoholism (Oxford, Oxfordshire) 46, 672679.

Sampson, T.R., Debelius, J.W., Thron, T., Janssen, S., Shastri, G.G., Ilhan, Z.E., Challis, C., Schretter, C.E., Rocha, S., Gradinaru, V., et al. (2016). Gut Microbiota Regulate Motor Deficits and Neuroinflammation in a Model of Parkinson's Disease. Cell 167, 1469-1480.e1412.

Schneider, C.A., Rasband, W.S., and Eliceiri, K.W. (2012). NIH Image to ImageJ: 25 years of image analysis. Nature methods 9, 671-675.

Shan, Z., Shi, P., Cuadra, A.E., Dong, Y., Lamont, G.J., Li, Q., Seth, D.M., Navar, L.G., Katovich, M.J., Sumners, C., et al. (2010). Involvement of the brain (pro)renin receptor in cardiovascular homeostasis. Circulation research 107, 934-938.

Siggins, G.R., Martin, G., Roberto, M., Nie, Z., Madamba, S., and De Lecea, L. (2003). Glutamatergic Transmission in Opiate and Alcohol Dependence. Annals of the New York Academy of Sciences 1003, 196-211.

Stocker, S.D., and Muntzel, M.S. (2013). Recording sympathetic nerve activity chronically in rats: surgery techniques, assessment of nerve activity, and quantification. American journal of physiology Heart and circulatory physiology 305, H1407-1416.

Strong, R., Rehwaldt, C., Wood, W.G., Sun, A.Y., and Sun, G.Y. (1987). Effects of ethanol on acetylcholine and GABA release: differences in the role of potassium. Alcohol and alcoholism (Oxford, Oxfordshire) Supplement 1, 631-635. 
Tombaugh, G.C., and Somjen, G.G. (1996). Effects of extracellular pH on voltage-gated Na+, K+ and Ca2+ currents in isolated rat CA1 neurons. The Journal of Physiology 493, 719-732.

van Marum, R.J. (2009). Update on the use of memantine in Alzheimer's disease. Neuropsychiatric Disease and Treatment 5, 237-247.

Wang, J., Du, H., Jiang, L., Ma, X., de Graaf, R.A., Behar, K.L., and Mason, G.F. (2013). Oxidation of ethanol in the rat brain and effects associated with chronic ethanol exposure. Proceedings of the National Academy of Sciences of the United States of America 110, 1444414449.

Webster, L.T., Jr. (1963). Studies of the acetyl coenzyme A synthetase reaction. I. Isolation and characterization of enzyme-bound acetyl adenylate. The Journal of biological chemistry 238 , 4010-4015.

Wiese, J.G., Shlipak, M.G., and Browner, W.S. (2000). The Alcohol Hangover. Annals of Internal Medicine 132, 897-902.

Zakhari, S. (2006). Overview: how is alcohol metabolized by the body? Alcohol research \& health : the journal of the National Institute on Alcohol Abuse and Alcoholism 29, 245-254.

Zehtabchi, S., Sinert, R., Baron, B.J., Paladino, L., and Yadav, K. (2005). Does ethanol explain the acidosis commonly seen in ethanol-intoxicated patients? Clinical toxicology (Philadelphia, Pa) 43, 161-166.

Zhou, X., Hollern, D., Liao, J., Andrechek, E., and Wang, H. (2013). NMDA receptor-mediated excitotoxicity depends on the coactivation of synaptic and extrasynaptic receptors. Cell Death Dis 4, e560. 